University of Louisville

ThinkIR: The University of Louisville's Institutional Repository

\title{
The new paradigm of rehabilitation : a meta-analysis of the effectiveness of incarceration-based rehabilitation in regards to recidivism reduction.
}

Shaun Andrew Dixon 1985-

University of Louisville

Follow this and additional works at: https://ir.library.louisville.edu/etd

\section{Recommended Citation}

Dixon, Shaun Andrew 1985-, "The new paradigm of rehabilitation : a meta-analysis of the effectiveness of incarceration-based rehabilitation in regards to recidivism reduction." (2013). Electronic Theses and Dissertations. Paper 357.

https://doi.org/10.18297/etd/357

This Master's Thesis is brought to you for free and open access by ThinkIR: The University of Louisville's Institutional Repository. It has been accepted for inclusion in Electronic Theses and Dissertations by an authorized administrator of ThinkIR: The University of Louisville's Institutional Repository. This title appears here courtesy of the author, who has retained all other copyrights. For more information, please contact thinkir@louisville.edu. 


\title{
THE NEW PARADIGM OF REHABILITATION A META-ANALYSIS OF THE EFFECTIVENESS OF INCARCERATION-BASED REHABILITATION IN REGARDS TO RECIDIVISM REDUCTION
}

\author{
By \\ Shaun Andrew Dixon \\ B.S. Sociology / Criminal Justice \\ University of Southern Indiana, 2008
}

\begin{abstract}
A Thesis
Submitted to the Faculty of the

College of Arts and Sciences of the University of Louisville

In Partial Fulfillment of the Requirements

for the Degree of
\end{abstract}

Master of Arts

Department of Sociology

University of Louisville

Louisville, Kentucky

August 2013 



\title{
THE NEW PARADIGM OF REHABILITATION \\ A META-ANALYSIS OF THE EFFECTIVENESS OF INCARCERATION-BASED REHABILITATION IN REGARDS TO RECIDIVISM REDUCTION
}

\author{
By \\ Shaun Andrew Dixon \\ B.S. Sociology / Criminal Justice \\ University of Southern Indiana, 2008
}

\section{A Thesis Approved on}

July 16, 2013

By the following Thesis Committee:

Thesis Chair: Dr. Ryan Schroeder

\author{
Dr. Dave Roelfs
}

Dr. Richard Tewksbury 


\title{
ABSTRACT \\ THE NEW PARADIGM OF REHABILITATION \\ A META-ANALYSIS OF THE EFFECTIVENESS OF INCARCERATION-BASED REHABILITATION IN REGARDS TO RECIDIVISM REDUCTION
}

\author{
Shaun A. Dixon
}

July 16,2013

This study is a meta-analytic examination of incarceration-based rehabilitation and its ability to reduce recidivism. Substance abuse is a large problem within our convict population; many times it is a substance related conviction that is the cause of the inmates' incarceration. Claims have been made for decades that if society can effectively rehabilitate these convicts, recidivism rates will be reduced, ultimately lowering incarceration rates.

By creating a stringent criterion of inclusion, this study makes an "apples-toapples" analysis of prior studies on the topic, examining twelve studies of incarcerationbased rehabilitation and their outcome variables. The data was synthesized through metaanalytic techniques to determine if the rehabilitative efforts of correctional institutions are effective at reducing recidivism. This study found, on average, those who receive incarceration-based rehabilitation are $43 \%$ less likely to recidivate than those inmates who did not receive incarceration-based rehabilitation $(\mathrm{p}<0.0001)$. My hypothesis that incarceration-based rehabilitation during the era of determinate sentencing will reduce recidivism has been substantiated. 


\section{TABLE OF CONTENTS}

PAGE

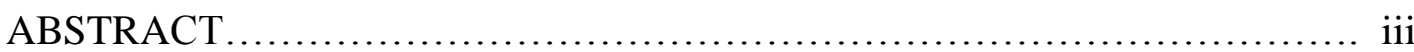

INTRODUCTION .................................................. 1

Scope of Prison Population................................................................ 1

Lower Recidivism and Crime Reduction Rooted in Rehabilitation.......... 1

Rehabilitation, Not a New Idea (Indeterminate Sentencing)................ 2

Structural Problems with the Rehabilitative Model......................... 3

Political Influence and the End of the Rehabilitative Model...............4

Shifting the Justice System Back to a Rehabilitative Model............... 6

Critical Components of Feasibility in Considering

Rehabilitative Programs.............................................. 8

Rehabilitation in a Correctional Setting..............................10

LITERATURE REVIEW ................................................ 19

Robert Martinson, "What Works?"”...................................19

Robert Martinson, "New Findings, New Views"........................ 24

Paul Gendreau and Robert Ross,

"Revivification of Rehabilitation: Evidence from the 1980's"..............26

D.A. Andrews et. al., "Does Correctional Treatment Work?".............. 28

Charles H. Logan and Gerald G. Gaes,

"Meta-Analysis and the Rehabilitation of Punishment"................... 31

Frank S. Pearson and Douglas S. Lipton

"Meta-Analytic Review of the effectiveness of Corrections-Based

Treatments for Drug Abuse" ........................................ 34

Duren Banks and Denise C. Gottfredson

Drug Treatment and Time to Rearrest............................... 35

Ojmarrh Mitchell, et. al. "Does Incarceration-Based Drug

Treatment Reduce Recidivism?" .................................... 36

THEORETICAL FRAMEWORK ....................................... 39

Labeling Theory................................................ 39

RESEARCH METHODOLOGY ........................................... 52

Meta-Analysis................................................ 52

1.A Research Question is Formed....................................53 


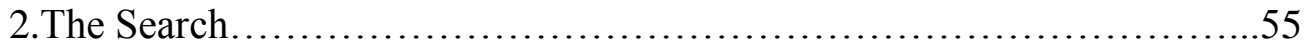

3.Inclusion Criteria and Scope of Study ................................56

$4 \& 5$. Coding Forms and Interviewing the Studies.......................59

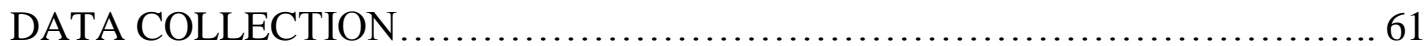

6.The Effect Size Statistic......................................... 61

7.Analyzing and Describing the Distributions of Effect Size................64

8.Analyzing Relationships with Moderator Variables......................65

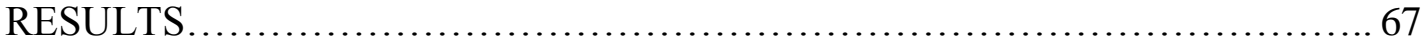

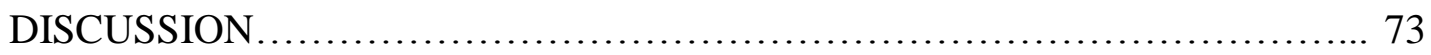

The Story Told by the Data.......................................... 73

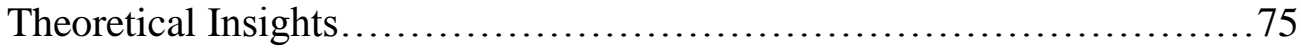

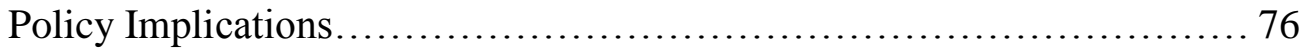

Limitations of This Study, Call For Further Research...................... 77

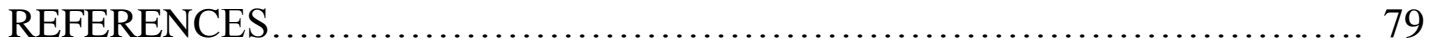

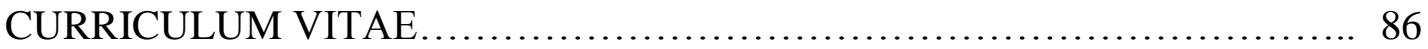




\section{INTRODUCTION}

\section{Scope of Prison Population and Drug Offenders}

Between 1.8 and 2 million American citizens are incarcerated on any given day in our correctional facilities, with over 5 million people currently under the justice system's supervision (Dyer 2000:1, Maruschak \& Parks 2012:1, Carson \& Sabol 2012:1 ). By comparison, the United States imprisons more of its citizens than any other country in the world, about five to seven times as many citizens as similar industrialized countries with comparable crime rates (Dyer 2000:2). The difference is these countries have chosen to deal with the majority of their non-violent offenders through various rehabilitative techniques, outside of prison. From 1971 to 2000, a 29 year span, the United States Correctional system increased in size ten-fold (Dyer 2000:1-2). Stephen Richards and Jeffery Ross attribute this increase to the two decades of aggressive criminal justice policies, specifically those of the war on drugs which served to largely increase the incarceration rate by simply defining substance abusing citizens as "enemies of the state" (2002:175). A 2009 study produced by the Bureau of Justice Statistics states that approximately $23 \%$ of all inmates currently incarcerated have been convicted solely of drug offenses (Sabol, West, and Cooper 2009:37-38).

\section{Lower Recidivism and Crime Reduction Rooted in Rehabilitation}

In a justice system where 50 percent of men released from correctional facilities will return within a year, it becomes obvious that something must be done to fix our incarceration problem (Ross 2002:155; Snyder 2011). There is an emerging agreement in the modern literature that most of the non-violent inmate population, especially drug 
offenders, could be better dealt with in a rehabilitative setting, often reducing their rate of recidivism, ultimately lowering correctional budgets substantially (Ross 2002:176; Dyer 2000:208; Austin 2001:248; Reiman and Leighton 2010:42; Mauer 2006:175). These claims are based on various studies, such as a 1994 study by the California Department of Alcohol and Drug Programs, that found for every dollar invested in substance abuse treatment it would save the state seven dollars in terms of crime reductions and reduced hospitalizations (State of California 1994:89). Another study by the Rand Corporation Drug Policy Research Center further supports this logic in finding, "treatment is seven times more cost-effective than domestic drug enforcement in reducing cocaine use and 15 times more cost-effective in reducing the social costs of crime and lost productivity" (Caulkins 1997:xvii).

\section{Rehabilitation, Not a New Idea (indeterminate sentencing)}

While the call for the justice system to incorporate a rehabilitative model for drug offenders is an emerging theme in modern criminological literature, it is not a new ideology. Rehabilitation was the key element in earlier correctional facilities under the era of indeterminate sentencing. Indeterminate sentencing was a correctional philosophy that described criminals as individuals who possessed deficiencies, deficiencies that could be treated. The predominant rationale of indeterminate sentencing was that if an inmate took advantage of social programs and strived to rehabilitate him/herself, then a reward system should be in place to encourage the speedy treatment of their deficiency (Mauer 2006:44). What better reward for a convict than to obtain an early release? As new literature emerges claiming that rehabilitation for drug offenders is the new cuttingedge way of handling these non-violent offenders within the justice system, it is certainly not a new theory or even a new ideology. Rehabilitative models have been implemented 
in correctional facilities for years under the indeterminate sentencing era as a means to an end for the convict (early release).

\section{Structural Problems with the Rehabilitative Model}

At the theoretical level, indeterminate sentencing was logically sound; however, at the functional level, it encountered multiple problems. First, the decision-making power of release dates were assigned to prison officials and parole boards, which would determine when the inmate had "responded to treatment" (Austin 2001:2). With the control of sentence lengths in the possession of such officials, release dates soon became a powerful bargaining tool for prison staff, and often release decisions were made on the basis of race, gender, and other factors (Mauer 2006:44).

Throughout this period of indeterminate sentencing, drug treatment and rehabilitation programs could be found in abundance in correctional facilities. This allowed for multiple studies to take place evaluating their effectiveness; however, by the late 60 's and early 70 's, such studies provided inconsistent results. Often criticizing the rehabilitation model, criminologists found that prison-based rehabilitation programs were not as effective as originally thought. "In general, they found that prisoners who participated in a wide range of rehabilitative programs were rearrested at the same rate as those who did not" (Austin 2001:92). At best estimates participants' recidivism rates were only reduced 5 to 10 percent by effective programs, compared to inmates who did not participate in such programs (Austin 2001:92). The second issue that several of the studies during this time indicated, was the inmate's motivations for being involved in rehabilitation programs, which could explain the large level of non-findings (inabilities to show that rehabilitation had any effect at all on the inmates, statistically insignificant) 
that most studies produced. If the motivation for participation was simply to obtain time reductions, then the key components of the rehabilitative model had already failed. The majority of rehabilitation programs require participants to identify their deficiencies or addictions as problems, and only then can rehabilitation begin (Nixon and Solowoniuk 2008:2; Alcoholics Anonymous 2001:59). The argument that Austin (2001:93) builds against rehabilitation during the indeterminate sentencing era is that time reductions were the inmate's main focus, rather than an emphasis on overcoming their addictions by utilizing the knowledge and skills provided through the rehabilitative programs. Most inmates would participate in these programs but the programs had no positive effect on overcoming their addictions post-release (Austin 2001:92).

Since the motivation for participation was an issue, rehabilitative programs simply became analogous to other standard daily activities such as lunch or yard time. The problem with studying such an activity and measuring the participants' recidivism rates would become apparent (we would expect an inability to refute the null hypothesis that the program had an effect on participant's recidivism rates).

\section{Political Influence and the End of the Rehabilitative Model}

By the mid- late 1970's, the problems and inconsistencies with indeterminate sentencing had become commonly known to both sides of the political spectrum. As an exception to historical American politics, the conservatives and liberals were both in agreement that indeterminate sentencing was coming to an end and society was in need of a more uniform sentencing method for criminals. However, with the political parties remaining true to their nature, they presented completely different ways of removing 
indeterminate sentencing and had different ideologies about the type of determinate sentencing that would replace it (Austin 2001:92).

The liberals of the time thought that shorter more uniform sentences, especially for non-violent offenders, should be instituted. A call to replace parole with unsupervised release was also a popular idea promoted by the liberal party. They identified the problems that were present during the indeterminate sentencing period and agreed on a harm reduction model to remove many of these biases affecting the inmate's lives and sentence lengths (Mauer 2006:47). If such a system were instituted, then a convict would know the exact time of his sentence and that time frame would go unchanged with the exception of minimal reductions for "good time". Once this system was in place, "liberals had no objection to prisoners partaking of any educational or vocational programs that might be offered in prison, since these would then be engaged in on a voluntary basis, and not tied to a release date" (Mauer 2006:47). The liberals and conservatives both acknowledged that rehabilitation was not effective during indeterminate sentencing, although the liberals agued it was effective, just not in a coercive atmosphere. The conservatives disagreed and held that it simply was not effective (Mauer 2006:46).

Conservatives often cited an influential work of the time by Robert Martinson in which he simply asked, what was working? In the earlier versions of his work, a work in which he revised several times, he found more or less that nothing worked (Mauer 2006:46). Martinson reported "with few and isolated exceptions, the rehabilitative efforts that have been reported so far have had no appreciable effect on rehabilitation" (Martinson 1974:25). Conservatives were in opposition "to rehabilitation and indeterminate sentencing because inmates were being released too quickly, only to prey 
again on the public, they insisted"(Austin 2001:92). By playing on the public's fear of violence, conservatives were easily able to promote their punitive, punishment oriented, lengthier sentences. With their political win, the conservatives instituted a determinate sentencing model and removed the costly rehabilitation and vocational programs from the correctional facilities. In addition, they manipulated the lengths of sentences by introducing strict parole policies, ultimately making inmates' stays longer (Austin 2001:92). Decades of this "getting tough" policy has served to increase prison populations to the record amount of 6.3 million people under the justice system's supervision (Maruschak and Parks 2012:1; Carson and Sabol 2012:1).

\section{Shifting the Justice System Back to a Rehabilitative Model}

More recently, a large movement has gained momentum for incorporating a quasi-rehabilitative model back into the correctional facilities. The logic behind this movement seems pretty sound on the surface. Such advocates identify the large prison population as a social problem, then break down the prison population to show the large sums of inmates who were convicted of drug crimes, or who were on drugs at the time they committed the crime. Advocates for rehabilitation claim that 70 percent of the prison population has some history of drug use or abuse and could benefit from rehabilitation (Austin 2001:164). As a result of this logic, advocates for rehabilitation have claimed that the best solution to address the overwhelming prison population would be to expand the availability of incarceration-based drug treatment services. In response, we have seen the implementation of programs such as treatment alternatives to prison (TAP), drug courts, and residential substance abuse programs. Many of these federally-funded programs maintain their popularity through their claims of reducing recidivism and prison cost in 
general. They are able to reduce the general prison cost through the diversion of offenders to alternative programs in hopes of reducing the likelihood of repeat offenses, thus reducing the potential future costs of the correctional system (Austin 2001:170).

A 1998 report released by the National Center on Addiction and Substance Abuse (CASA) helped the rehabilitative model once again gain popularity by claiming that there are such great cost-savings benefits from rehabilitation. Only 10 percent of inmates entering drug treatment have to successfully complete the program and not recidivate for the programs implementation to be justified. In addition, the Residential Substance Abuse Treatment programs (RSAT) were instituted to provide an estimated \$250 million dollars from 2001-2006 toward comprehensive treatment programs for inmates (Austin 2001:170).

As with any report, there are certain assumptions that must be taken into consideration to comprise the credibility of the overall statements, especially those that influence government spending. This is the case with the claims expressed by the CASA. For the CASA's statements to hold true, statisticians have made a few assumptions, assumptions we should discuss so readers understand why such bold claims are made. The CASA assumes that each drug user is committing 100 crimes a year at an average cost to society of $\$ 50$ per crime (this estimate seems high since often drug crimes are victimless crimes, posing no cost to society, much less a $\$ 50$ crime every three to four days). Furthermore, they take into account the salary of the justice personnel and court cost associated with arresting and prosecuting that specific drug user at least twice within the year (however, if guilty and convicted, many offenders will not be arrested and processed a second time within a year). Additionally, the CASA assumes the drug user 
will be incarcerated for a term of at least 1 year if gone untreated consequently adding in the cost of feeding, and housing a convict over a period of a year. Conversely, it assumes that those who are treated will gain employment with a minimum annual salary of $\$ 21,400$ and contribute taxes to the economy (it becomes hard to buy into convicts becoming immediately employed upon release in positions paying well above the minimum wage, especially during a competitive job market). As one can see, these great claims do not quite hold up under close scrutiny, and are heavily biased toward the rehabilitative model (Austin 2001:170).

\section{Critical Components of Feasibility in Considering Rehabilitative Programs} When considering the institution of rehabilitative programs in correctional facilities, a researcher must remain objective. First and foremost, the core argument should be identified and examined. The origination of this logic is that many of the convicts serving time are drug abusers and that they commit a large number of crimes resulting from their drug use. Next, it is assumed that these inmates would take advantage of drug treatment programs if provided. Lastly, it is hypothesized that these convicts will continue to commit crime upon release if they go untreated; however, if they are treated recidivism rates will drop substantially (Austin 2001:169).

First, we must ask if the current prison population has a drug abuse problem. The "CASA reports that approximately 70 to 80 percent of all inmates (prisons and jail) have either committed a crime while under the influence of drugs, committed a drug related crime, or used a drug on a regular basis" (Austin 2001:170). In order to cross check this statistic against CASA's findings, data from a 1996 ONDCP study found that $59.5 \%$ of federal prisoners and $22.3 \%$ of state prisoners had been convicted of drug related crimes 
(McCaffery 1998). Furthermore, a third reference from the National Institute of Justice provided a more current statistic from 2003 , stating that $80 \%$ of inmates in federal and state prisons had reported substance abuse or addiction (Bureau of Justice Assistance 2005:1).

By triangulating the resources of this statistic, it has been determined that $70 \%$ to $80 \%$ is an accurate assumption for the number of inmates who have substance abuse or addiction issues. Since this statistic represents a majority of the prison population, the core argument that many inmates have drug abuse problems is substantiated.

Next, it must be determined that there is even a market for rehabilitation in a correctional facility setting. Due to the nature of determinate sentencing, a time reduction for participation in such programs is often non-existent (with exceptions of discretionary releases by parole boards), thus diminishing the incentive for participation. Other inmates, for a variety of reasons related to prison operations and safety concerns, may not be allowed to participate in rehabilitative programs. Then there will be several inmates who will simply drop-out or fail to complete their programs (Austin 2001:171). Issues such as these could drastically reduce program eligibility, limiting the overall success rates of rehabilitative programs, and reduce the cost-benefit ratios for implementation of such programs.

Once again, the CASA's estimates of who could benefit from rehabilitation are heavily skewed in an effort to support the advocating of such programs. Austin outlines multiple specific factors that quickly limit the CASA's estimate of 1.2 million inmates eligible for rehabilitation down to 73,500 inmates (2001:174). With the lack of sufficient markets for rehabilitation, legitimizing its usefulness soon becomes a more difficult than 
expected task for advocates. The number of inmates actually eligible to participate in rehabilitative programs realistically only represents a small proportion of the prison population less than $5 \%$ by Austin's estimates. This can be cross checked with the figures from a Michigan Department of Corrections (DOC) study that found $85 \%$ of their inmate population would be ineligible for participation in a Therapeutic Community (TC) type rehabilitation under the Residential Substance Abuse Treatment (RSAT) guidelines with the largest exclusionary factor being the time left to serve (Austin 2001:174).

The last and most critical assumption that will be examined further by this study is that treatment will show a significant effect of reducing recidivism and post-release drug use, resulting in overall lowered criminal behavior. Essentially, I will am seeking to evaluate prior studies from the determinate sentencing era, providing empirical evidence of the effectiveness of drug treatment programs in the correctional setting using metaanalytic techniques. Unlike specific studies that narrow their focus to certain programs at limited institutions, this study will utilize a meta-analytic approach to offer an "acrossthe-board" evaluation of incarceration-based rehabilitation.

\section{Rehabilitation in a Correctional Setting}

With many of the inmates having substance abuse problems, the general concern becomes that without treatment, these drug-involved offenders will resume drug use and criminal activity upon release, inevitably paving the way for their return to the justice system. Federal grants and the implementation of the Residential Substance Abuse Treatment (RSAT) program help to make prison rehabilitation a reality for inmates. The research showing that prison-based therapeutic community programs can significantly 
lower recidivism and post-release drug use encourages the development of the residential treatment model (Lipton 1998).

Historically a "therapeutic community" (TC) has not been exclusive to a correctional setting. Sanctuaries, group homes, and specialized schools have all been referred to as a TC. Pearson and Lipton (1999:387) provide a good definition of a therapeutic community it is as follows;

A TC is a group-based residential program with residents involved in all aspects of the group's operations, including administration and maintenance. Crime and drug abuse are seen as symptomatic of a disorder of the whole person so the treatment problem to be addressed is the person, not the drug. The key to solving the person's problem is right living. Right living develops from committing oneself to the values of the TC, including both positive social values such as the work ethic, social productivity, and communal responsibility to oneself and significant others. TCs are hierarchically organized and stratified. Staff and resident roles are aligned in a clear chain of command. New residents are assigned to work teams with the lowest status, but they can move up strata as they demonstrate increased competency and emotional growth. Thus, they have an incentive to earn better work positions, associated rights and privileges, and living accommodations. The program uses groups and meetings to provide positive persuasion to change behavior, and it uses confrontation by peer groups whenever values or rules are breached. On the other hand, peers also provide supportive feedback such as reinforcement, affirmation, instruction and suggestions for changing behavior and attitudes, and assistance during group meetings as residents recall painful memories from childhood and adolescence.

TCs have also been used to treat a wide range of special needs populations. For example, TCs have been utilized with HIV/AIDS patients, Hepatitis C patients, the mentally ill, substance abusers, criminal justice populations, the homeless, the physically handicapped, gang involved individuals, the elderly, veterans, and even new mothers (Warr 2011:19). The term "therapeutic community" was coined by Thomas Main in 1946, as he combined community therapy with ongoing psychoanalytic psychotherapy while treating WWII military veterans who had serious neurotic conditions resulting from their experiences in combat. Maxwell Jones and others were also credited with modifications 
to therapeutic work in a community setting around the same time, and TCs would become commonplace in many British psychiatric hospitals by 1954 (Lipton 1998). The United Kingdom utilized the TCs philosophy in other disciplines towards the late 1950's. Grendon Prison, built in 1959, allocated several portions of the prison to TCs that would provide treatment to the psychologically disturbed offenders (Lipton 1998).

The British TCs operated as a democratic therapeutic community (DTC). DTCs principles consisted of allowing the community members to have a direct say in how every aspect of the wing was run. They were fairly tolerant of member's mistakes, and encouraged members to accept themselves as flawed and support each other regardless. Responsibility and accountability were strongly encouraged, while rule breaking was frowned upon. Peer influence was utilized to reinforce the community's cultural values. Members who had successfully completed the program returned to play the supportive roles of the TC. Therapeutic goals of the DTC include the following: "getting past denial; relief of intrapsychic distress; developing relationships with women and children, authority figures and one another; changing attitudes toward offending, and specifically to one's primary offense; building morality, victim awareness, contrition and understanding of effects on victims; and relapse prevention" (Lipton 1998:2). At Grendon Prison, the treatment lasted for a minimum of two years. The inmates were placed in small groups of ten residents monitored by two staff members. They had "daily community wing meetings of 35 to 42 ; feedbacks or confrontation sessions; and cognitive skills, psychodrama, social and life skills, alternatives to violence and educational programming” (Lipton 1998:2). 
American TCs vary from those found in Europe. "Charles Dederich, a recovered alcoholic who, unfulfilled by Alcoholics Anonymous, founded his own racially integrated community of former addicts and ex-offenders" (Lipton 1998:2) in 1958 called Synanon. Synanon is a form of group therapy with "intense emotional catharsis-type participation sessions; fairly brutal confrontation sessions; educational seminars; and discussions, not of drugs, but of self-image, work habits, and self-reliance" (Lipton 1998:2). The U.S. TC model focuses less on psychoanalytic and psychotherapeutic aspects than the British model. Rather than a concentration on criminal offense or substance abuse, the U.S. model seeks a more holistic tactic with emphasis on self-help, lifestyle changes, and social learning. They operate more in a hierarchical structure than a democratic one, and instead of rooting itself in a medical/ psychiatric approach, the U.S. TC comes from a recovered client self-help background (Lipton 1998:3).

The federal penitentiary in Marion, IL began the first U.S. TC model program in 1969, developed and implemented by Dr. Martin Groder, a prison psychiatrist. The program was based on his experiences in California, combining concepts from transactional analysis training and intensive group counseling, called the "Aesklepieian" model. While it did not meet the criteria of modern day TCs, it did offer insight as a stepping stone for many of the mid-1970's TC programs (Lipton 1998:3). Throughout the 1970's and 80's, a variety of TC models existed: Aesklepieian, Phoenix House, Daytop, and Stay'n Out. Many states such as Arkansas, Connecticut, Georgia, Michigan, Missouri, Nebraska, Florida, New York, Oklahoma, Oregon, South Carolina, and Virginia tried instituting TCs in the prison setting. The average lifespan of the TCs during this time were five to seven years (Lipton 1998:4). Lipton (1998:4) tells that often times the 
TCs were closed due to funding issues, or in some cases administrative priorities migrated away from the rehabilitative model. A few TCs demised due to procedural issues such as administrative corruption or the lack of security that allowed for contraband to infiltrate the facility, while others simply were never able to create an operational sense of community.

The implementation of the Residential Substance Abuse Treatment for State Prisoners Program in 1994 allowed funds for states to develop and improve their substance abuse programs with the prison and jails. The federal guidelines for RSAT encouraged states to implement a comprehensive substance abuse treatment program. A program that included life skills development, vocational training, relapse prevention, and aftercare services (Gonzales, Henke, and Herraiz 2005:1). Certain criteria must be met for state correctional agencies to be eligible for funds they are as follows:

- The program must last between 6 and 12 months. - Eligible participants will have between 6 and 12 months left to serve of their sentence, this is so the participant can be released following their completion of the RSAT program, instead of being placed back into the general prison population.

- Residential treatment facilities must be separated from the general correctional population and dedicated exclusively to the program.

- The program must focus on inmates' substance abuse problems.

- Substance abuse and related problems should be solved by developing the participants' cognitive, behavioral, social, vocational, and other related skills.

- The program will require reliable drug and alcohol screening such as urinalysis during and after the participants incarceration period. - Subgrant applicants who provide aftercare services will be given preference when it comes to funds allocation. (Gonzales, Henke, and Herraiz 2005:4) 
Jail-based substance abuse programs are also eligible for funds under the RSAT grant. However, while similar, their requirements do vary from the state prison system slightly and are as follows:

- The program must last at least 3 months.

- Once again the RSAT participants must be separated from the general correctional population.

- Jail-based programs must also focus on inmates' substance abuse problems.

- Jail-based programs must also develop inmates' cognitive, behavioral, social, vocational, and other related skills in order to address the inmates' substance abuse problems.

- The programs must also be science-based and effective. (Gonzales, Henke, and Herraiz 2005:4)

There are a multitude of treatment modalities that institutions may adopt. Each modality incorporates its own variety of therapeutic approaches. The most common types of correctional therapy are cognitive therapy, behavioral therapy, reality therapy, solutionfocused, family systems, feminists therapy, and faith-based therapy (Hanser 2010:294). Cognitive therapy seeks to correct faulty thinking patterns and belief systems, ultimately resulting in behavioral changes. Behavioral therapy focuses on the offenders long-term behaviors and is rooted in social learning theory. In order to correct the offender's maladapted behavior, new behaviors are taught and reinforced. If this is maintained over a long enough period of time, the belief is that the new behavioral practices will replace the problematic old behaviors. Reality therapy teaches responsibility by holding a strong conviction of rejecting the offender's excuses, neutralization of problems, unrealistic rationale, and irresponsible behaviors. The reality therapist forces the offender to accept full responsibility for his or her actions, and teaches the offender how to fulfill needs within the limits set by reality. Solution-focused treatment believes that most 
psychological problems are present only intermittently, and focuses on the times in which they are absent. The therapist works with the offender to help them recognize these times of psychological clarity and tries to make them more frequent, predictable, and controllable. Family-systems therapy recognizes the family as a system with its own values, beliefs, and dynamics that affect the offender more than any other social group. The therapist helps the offender identify their role within the family system and the responsibilities associated with that role in order to facilitate a positive change. Family systems therapy has been found to be particularly effective with substance abusers and females with children (Hanser 2010:295). Feminist therapy is exclusive to the female population and relies on the underlying assumption that many of the female offenders were victims themselves (childhood sexual abuse or domestically abusive relationships). Feminist therapy seeks to empower these women by strengthening communication skills, self-esteem, relationships, and giving them a sense of assertiveness. Faith-Based therapy employs scriptural instructions on appropriate cognition and behavior as a vehicle for change (Hanser 2010:294-295).

It is also important to understand the dynamics of the community as a method for change. Since the TC uses a holistic approach treating the whole person rather than just an addiction, it allows the offender to become part of something that is greater than just oneself. This makes the "TC the method for change, not the treatment specialist or the individual" (Warr 2011:44). "Clients in a TC are members, as in a family setting, they are not patients, as in an institution. These members play a significant role in managing the TC and act as positive role models for others to emulate" (Warr 2011:17). The community members interact in structured and unstructured ways to influence the 
attitudes, perceptions, and behaviors of others. The hierarchical structure requires members to exhibit responsibility to their mentors and team leaders. Accountability is another function of the community by demanding participation in community meetings, work details, and educational opportunities (Warr 2011:51). There are eight concepts within the community itself that are functional in facilitating change, which are as follows:

1. Use of participants roles

2. Use of membership feedback

3. Use of membership as role models

4. Use of collective formats for guiding individual change

5. Use of shared norms and values

6. Use of structure and systems

7. Use of open communication

8. Use of relationships (Warr 2011:56).

The most popular RSAT treatment module is referred to as Thinking for a

Change. This model integrates a cognitive behavior curriculum (Gonzales, Henke, and Herraiz 2005:7). While programs vary somewhat from facility to facility, most focus on cognitive restructuring, developing social skills, and enhancing problem solving capabilities. Current RSAT programs:

educate inmates about substance abuse, including its consequences, the addiction cycle, recovery, the relationship of alcohol and drug abuse to other problems, and how to work through denial of and blaming others for abuse problems. They help participants understand behaviors such as anger, criminal thinking, and poor skill and habit development. They teach offenders how to manage anger, stress, and emotions; resolve conflicts; and set goals and boundaries. They help participants develop social, communication, coping skills. Some programs reinforce positive behaviors instead of focusing on negative ones. Relapse prevention is taught in many, if not all, RSAT programs. Many also include 12-step programs such as Alcoholics Anonymous or Narcotics Anonymous (Gonzales, Henke, and Herraiz 2005:7).

Some programs go a step further to include components focusing of family issues such as parenting, domestic violence, developing relationships, and communication. 
Occasionally, programs may even incorporate family therapy sessions into its curriculum. Other optional components that are sometimes integrated are educational, vocational, and employment assistance. This consists of teaching the inmates financial management, General Education Development (GED) courses, job training, and work release programs. Programs that focus on juvenile populations often incorporate a writing exercise, such as maintaining a daily journal (Gonzales, Henke, and Herraiz 2005:8). Under RSAT guidelines, the programs should have prerelease planning, transitional services, and a strong focus on case management to help the participants reenter their communities upon release. Offenders should be introduced to multiple community resources to insure their post release success; these resources may include mentors, role models, peer support groups, mental health care, childcare, transportation substance-free recreational activities and facilities, as well as housing assistance (Gonzales, Henke, and Herraiz 2005:8). 


\section{LITERATURE REVIEW}

\section{Robert Martinson}

\section{What Works? - Questions and Answers about Prison reform}

In 1974, Robert Martinson examined rehabilitation in the prison setting. Since

then, Martinson's article has been referred to as one of the most cited but least read (in its entirety) articles ever published (Cousineau and Plecas 1982). The article stemmed from a 1966 study organized by the New York State Governor's Special Committee on Criminal Offenders. The problem the committee needed to address was the lack of scholarly literature available on the most effective types of rehabilitation. Martinson and his colleagues were hired by the committee to provide a comprehensive survey of what was known about rehabilitation. Once the study was complete, the state had decided that its findings did not line up with their interests, so the conclusions found by Martinson were dismissed and the state carried forward with their specialized programs that had already been implemented in the meantime. By 1972, the state had not yet published the study and refused Martinson's request for permission to publish on his own accord. It would not be until attorney Joseph Alan Kaplon subpoenaed the study as evidence before the Bronx Supreme Court that the state of New York would allow permission for its publication. Martinson submitted this journal article as a summary of the original 1,400 page manuscript (1974:23).

In this article, Martinson identifies the large sums of literature available on multiple types of rehabilitations. He examines the conditions they have been implemented in, and the outcomes of specific programs. However, Martinson found what 
was lacking was a comprehensive review of this literature, so he set out to synthesize the research in order to determine "What Works?" Martinson engaged in a six month review of the literature looking for articles that were published in English, from any country, between 1945-1967, maintained methodology acceptable by social science standards, evaluated a treatment program, contained a control group for comparison, and had an outcome variable of recidivism. Upon finishing his search, Martinson compiled 231 studies that met his criteria for inclusion (1974:24).

Immediately, Martinson warns of the inconsistencies of combining such studies. He tells us that the groups studied are "exceedingly disparate, so that it is hard to tell whether what 'works' for one kind of offender will also work for others" (1974:24). He also immediately acknowledges the shortcoming of the recidivism outcome variable, stating that even though the same term is used from study to study, it may not apply to the same variable or measure. The term recidivism, as a measure, is still an issue researchers debate today, as rearrested could be considered recidivism, but reincarceration could also be used as a measure of recidivism, two totally different variables but the same term.

Regardless, Martinson goes on to give us a rough summary of the findings: "With few and isolated exceptions, the rehabilitative efforts that have been reported so far have had no appreciable effect on recidivism" (1974:25). Martinson follows this statement with the specific findings of each type of rehabilitation examined. After cautioning that we cannot know if the failure lies in the program itself or the conditions under which it is administered, he declares that the educational and vocational programs have produced no 
evidence leading us to believe that they have decreased recidivism at all (1974:28). Next, he outlined the specific findings of his examination into group and individual counseling:

These programs seem to work best when they are new, when their subjects are amendable to treatment in the first place, and when the counselors are not only trained but 'good' people as well. Such findings, which would not be much of a surprise to a student of organization or personality, are hardly encouraging for a policy planner who must adopt measures that are generally applicable, that are capable of being successfully institutionalized, and that must rely for personnel on something other than the exceptional individual (1974:32).

Martinson also looked into the transformation of the institutional environment as a factor. A popular program of his time was "milieu therapy," where every aspect of the inmates' environment is part of his/her treatment. There are no distinctions between the custodial staff and the treatment staff; this in turn is supposed to create a supportive, nonauthoritarian, and non-regimented atmosphere. The other inmates are also utilized to provide a positive peer influence and assist in the formation of constructive values. After rigorous examination, Martinson determined that these types of programs, at very least, do no worse than the alternative traditional incarceration at reducing recidivism. He did, however, determine that many of the "milieu therapy" programs operated on a fraction of the budget that regular institutions operated on, substantiating the program "not on grounds of rehabilitation but on grounds of cost-effectiveness" (1974:35).

Another popular treatment philosophy of the time was found in the medical sphere consisting of multiple surgeries and drugs as types of rehabilitative treatments. Martinson felt the two most common forms of these had enough literature available and were worthwhile to investigate. The surgical model was a castration of male sex offenders. When compared to a control group that had a 50.6 percent recidivism rate, those who were castrated only had a 3.5 percent recidivism rate (1974:36). Although 
effective, Martinson acknowledged the extreme policy implications the surgical model could encounter. Ultimately, castration was not a practical form of treatment, therefore rendering it ineffective. The administration of drugs, specifically tranquilizers, was also a popular method of treatment that was being utilized in youth. However, Martinson determined that while males showed an initial improvement from the control group, this disappeared at the length of one year. The tranquilizers actually provided higher recidivism rates among females than in the control group.

Advocates for harsher sentences began making claims that longer sentences would provide the additional deterrence effectively reducing recidivism. Martinson challenged this treatment ideology by examining the effect longer sentences had on recidivism. He found that;

these studies deal not only with different types and categorizations of offenders but different types of institutions as well. No more than in the case of institution type can we say that length of sentence has a clear relationship to recidivism (1974:38).

Some advocates for a decarceration ideology arose, explaining that parole sets the inmates up for failure after release, that a "Decarceration" of the convict would reduce the recidivism rate. Martinson determined that in one case, this showed no more of a positive effect than the control group had presented; however, in two other cases, the inmates that were "decarcerated" actually recidivated at a higher rate than the control group (1974:39). Additionally, he looked at probation instead of prison and determined that probation and supervision work sometimes with some offenders; however, intensive supervision does not work (1974:44). 
Another type of program of the time was community-based psychotherapy, the philosophy that removing the correctional facility and subjecting convicts to psychotherapy would reduce the recidivism rate. This was not effective; in fact, it actually provided higher recidivism rates than the control group.

In short, Martinson finds that we have very little reason to hope rehabilitation will decrease the recidivism rates: "This is not to say that we found no instances of success or partial success; it is only to say that these incidents have been isolated, producing no clear pattern to indicate the efficacy of any particular method of treatment" (1974:49). Martinson goes on to explain that the rehabilitative ideology is rooted in a theory that claims crime is a "disease", something abnormal that can be cured. To Martinson, this ignores the idea that crime is a normal function of society; it is the individual's responses to conditions of society, responses we have labeled "criminal". The best way to deal with crime, Martinson believes, is within the realm of the deterrence theory as he states in closing;

One cannot ignore the fact that the punishment of offenders is the major means we have for deterring incipient offenders. We know almost nothing about the 'deterrent effect,' largely because 'treatment' theories have so dominated our research, and 'deterrence' theories have been relegated to the status of a historical curiosity. Since we have almost no idea of the deterrent functions that our system performs or that future strategies might be able to perform, it is possible that there is indeed something that works - that to some extent is working right now in front of our noses, and that might be made to work better - something that deters rather than cures, something that does not so much reform convicted offenders as revent criminal behavior in the first place. But whether that is the case and, if it is, what strategies will be found to make our deterrence system work better than it does now, are questions we will not be able to answer with data until a new family of studies has been brought into existence. As we begin to learn the facts, we will be in a better position than we are now to judge to what degree the prison has become an anachronism and can be replaced by more effective means of social control (1974:50). 


\section{Robert Martinson}

New Findings, New Views: A Note of Caution Regarding Sentencing Reform

Five years following his publication of What Works? Martinson published this

article, mainly to recant his former position on rehabilitation. In this article, we are told "contrary to my previous position, some treatment programs do have an appreciable effect on recidivism. Some programs are indeed beneficial; of equal or greater significance, some programs are harmful" (1979:244). As a running theme of this article, he admits many of the complications he originally warned against are much more detrimental to the data than initially thought. Among these are his methodology, the use of recidivism as a measure, and the combining of juvenile data with adult data.

Martinson tells us that he used a different methodology than he did before to essentially re-examine the same type of data. The Effectiveness of Correctional Treatment (ECT) was the original study in which his article What Works? was based. Martinson claims his findings in the original study were derived from evaluation research, a "special kind of research which was applied to criminal justice on a wide scale for the first time in California during the period immediately following World War II. This research is experimental - that is, offenders are often randomly allocated to treatment and nontreatment groups so that comparison can be made of outcome" (1979:253).

His new study addresses many of these former issues, first by changing the recidivism outcome variable to a more accurately narrowed variable he calls reprocessing. Reprocessing refers to the process of a convicted offender being released into the community, then becoming reprocessed into the justice system at any level (i.e. arrest, having charges filed, or incarceration). Martinson also utilized a different sample in this later study. Originally, in ECT Martinson only used studies that contained 
evaluation research; in this work he included any study of at least ten individuals that contained a verifiable reprocessing rate. The original use of evaluation research was utilized, as it was believed that this was the only method found to show causation. Since ECT, Martinson has retracted this statement saying that there are more accurate ways of showing causation other than evaluation research. These rates were compared not to a control group but to a group of inmates that are involved in "standard processing," a method that Martinson claims to provide a sample much more representative of the general criminal justice system nationally (1979:253). Martinson goes on to state; "The law is a practical instrumentality of human devising, and often must employ arbitrary cutting points to make decisions on complex issues. The difference between juvenile and adult status may be a matter of a few years for many, but it is a matter of weeks or days for some. Yet, as we have shown, there can be grotesque disparities in the way similar groups of juvenile and adult offenders are reprocessed... is an object lesson in how far justice can stray from the American ideal of fair and equal treatment (1979:248)."

Martinson revisits one of his original claims by reinforcing it, claiming that he still believes to some extent that our current system is working on some level and still believes it is a worthwhile endeavor to strive to understand the current system prior to trying to change it. He does, however, protest against the misconstrued use of his research to claim that "nothing works". Martinson's newest findings are that some treatments work sometimes, with some offenders, in certain settings. The application of the treatment along with the conditions under which it is implemented are the largest predictors of the effectiveness of the program. His final conclusion is; 
The current system of sentencing in the United States must be reformed. Not only are the individual offenders treated disparately, but classes of offenders are treated disparately as well. Yet any reform must be approached with caution. The reprocessing rate is low and while some programs are beneficial under certain conditions, others can be distinctly harmful. In fact, some recent reforms show evidence of increasing the reprocessing rate, rather than decreasing it. Thus great care must be taken when introducing alternatives to our standard procedures probation, imprisonment, and parole supervision. Those treatments that are helpful must be carefully discerned and increased; those that are harmful or impotent eliminated (1979:258).

\section{Paul Gendreau and Robert R. Ross Revivification of Rehabilitation: Evidence from the 1980's}

Paul Gendreau and Robert Ross presented a publication in 1987 to review and

reevaluate the implementation of rehabilitation in correctional settings. They identify and refer to Martinson's original "What Works?" article as well as cite his revisions presented in 1979. Furthermore, they go on to provide several works brought forth since Martinson's 1979 article, showing that sometimes in certain settings some things work. Articles examining probation practices (Clear and Gallagher 1985), classification issues (Palmer 1984), work incentives and education programs (Linden and Perry 1982; Orsagh and Marsden 1985), program implementation issues (Van Voorhis 1987), and rights to rehabilitation (Rotman 1986) were used to substantiate the identification of a renewed trend within the literature showing support once again for the possibilities of rehabilitation within the correctional system (Gendreau and Ross 1987:351). Gendreau and Ross provide us with a word of caution that should be kept in mind when evaluating any research that has been affected or may affect government policy. They do so by identifying the possible latent effects that may still be lingering in the justice system due to Martinson's original "What works?" article; 
In addition, we should not forget that the reviews in the late 70's were based on studies that were conducted before the "nothing works" ideology might have affected much of the funding for rehabilitative programs. As a result, an incubation effect may have occurred, depriving the current treatment literature of persuasive evidence; therefore the present optimism may be based on little substance (1987:351).

Gendreau and Ross perform their meta-analysis to update the current status of what is known about "What works?" They collected peer-reviewed published articles dated from 1981-87 through a library search. To be included, the studies had to contain an outcome variable of re-arrest, reconviction, re-incarceration, or self-report of illegal behavior. They also must have a control group and post-treatment follow-up for comparison. Gendreau and Ross did not include research from what Sechrest, White, and Brown (1979) refer to as "fugitive" literature, which is essentially government documents that have not undergone formal peer review (Gendereau and Ross 1987).

Gendreau and Ross offer a critical approach to the meta-analytic method. While they support the ideas of some who view meta-analysis as a methodological breakthrough (Fiske and Sundeen 1982), they address the issues with prior qualitative methods used to evaluate the literature (Glass, McGraw, and Smith 1981). "Meta-analysis forces researchers to evaluate literature more carefully in a quantitative mode that is open to replication" (Gendreau and Ross 1987:391). They do, however, caution that the method is not without flaw. Bias may still occur due to the decisions a researcher has to make in the selection of literature, coding methods (Logan and Gaes 1993), and the interpretations of studies that vary in methodological quality (Gendreau and Ross 1987:391). They also acknowledge a popular critique of meta-analysis by Lipsey (1985 and 1986), in which Lipsey (1985) was confronted with the problem of "when an effect size was too small to detect, but too big to neglect" (Gendreau and Ross 1987:391). They admit that the 
interpretation of the effect size statistic, the generally accepted outcome variable for meta-analysis, can still be problematic (Gendreau and Ross 1987:391).

In concluding they revoke the claim "Nothing works", stating that "The principles underlying effective rehabilitation generalize across far too many intervention strategies and offender samples to be dismissed as trivial (Gendreau and Ross 1987:395)." They go on to advise that many of the experimentally successful programs can and have encountered detrimental problems when administered to a general population by government and private agencies. Gendreau and Ross close by advising criminologists that constant research is needed on this topic to track the constructive developments in rehabilitation among offenders.

\section{D.A. Andrews, Ivan Zinger, Robert D. Hoge, James Bonta, Paul Gendreau, Francis T. Cullen}

\section{Does Correctional Treatment Work? A Clinically relevant and Psychologically} Informed Meta-Analysis

Andrews' study is a revision of an earlier work of Whitehead and Lab (1989),

which attempted to assess the recidivism rates for those individuals who were placed in specialized treatment. The analysis of the treatment was unique; it took into account the offender's risk, need, and responsivity. This study demonstrates the limitations of the meta-analytic method can adversely affect the researcher's ability to introduce new variables. In contrast to Whitehead and Lab (1989), Andrews' findings may not weigh in heavily on the present study since much of his data is from juvenile samples and he excluded studies in his meta-analysis that focused on the treatment of substance abuse (which is the focus of this meta-analysis). However, it is important to look at Andrews' methodology so we can get a better idea of what meta-analyses can and cannot do statistically. 
Andrews' et. al. did introduce a new technique to this type of meta-analysis, a technique of which they claimed could provide a "check on the generalizability of any findings" (1990:377). Had better methodology been employed, this could have been a successful endeavor; however, due to their subjective terms, vague definitions, circular reasoning, and the inconsistencies of the comparative groups, many criticisms have arisen from this study (Logan and Gaes 1993). First, a sample of 45 studies of juvenile treatments that had appeared in professional journals between 1975 and 1984 containing binary measures of recidivism were compared to a sample of 35 studies of adult treatment from research files during the time period of 1950 to 1989 that employed binary measures of recidivism.

Furthermore, Andrews et.al. employs a coding method that introduces variables with subjective definitions. Even worse, these variables contain values composed from the results of their findings. Here is where they encounter their largest criticisms. They code for many of the variables that should appear in their analysis, such as the correctional setting, the year of the publication, the quality of the research design within each study, the justice system (adult/juvenile), and the intervention type. All of these are quantifiable variables; however, what follows is the downfall of the study. Andrews' et. al. attempted to apply a variable to measure the appropriateness of a treatment method for the individuals in which treatment was applied. A treatment was coded appropriate if it included any of the four conditions: "(1) service delivery to high risk cases, (2) all behavioral programs (except those involving delivery of service to lower risk cases), (3) comparisons reflecting specific responsivity-treatment comparisons, and (4) non 
behavioral programs that clearly stated that criminogenic need was targeted and that structured intervention was employed (Andrews et. al. 1990:379)."

Logan and Gaes (1993) identify the apparent circular reasoning that surrounds this variable: "Is treatment effective because it is 'appropriate', or is it called 'appropriate' when it is seen to be effective (1993:248)?" The variable may have been a legitimate measure had a treatment been determined or designed to be appropriate prior to finding the effectiveness for said treatment. Unfortunately, this is not how Andrews' et.al. had designed their coding for the variable; instead, the treatment was deemed "appropriate or inappropriate according to its relation to the factors of 'risk', 'responsivity', and 'need' (Logan and Gaes 1993:249)." Now the really confusing and flawed portion of the study surfaces within the terminology of these variables. Risk and responsivity were determined based on the outcome of effectiveness, but were distinguished from each other by their differential relation to outcome. Using the example presented by Logan and Gaes (1993), risk is identified as a factor that provided a predictive property of recidivism independent from treatment; responsivity is a factor that interacted with treatment to influence recidivism. This provided heavy inconsistencies within the coding method, the exact same variable such as age could be coded differently from study to study within the meta-analysis. In one study age affected the recidivism rates independently of the treatment method, so it was coded as a "risk" factor. In another study the treatment effect on recidivism varied in magnitude by age. In this case the exact same variable of "age" was coded as a responsivity variable (Logan and Gaes 1993:249).

Altogether Andrews' et. al. found that the treatment effect on recidivism had only a small correlation to the quality of the research design. They also found that the effect 
size, negative or positive, maintained a significant relation to the treatment type. To be more specific, they claimed that they had determined "what works", and found that the treatment effects on recidivism were strongest and most positive when they were "appropriate" (Logan and Gaes 1993:248).

Logan and Gaes (1993) critique this type of finding by referring to the aforementioned problems. Andrews et. al.'s findings provide that treatment is only likely to be effective when the offender needs to change, wants to change, and is amenable to change. Correspondingly that offender must receive treatment that matches their need, desire, and amenability to change. Logan tells us that we are not actually far removed from the stage of "nothing works" or "we don't know what works". So altogether while Andrews et. al. provides us with a perfectly legitimate study, they provide no real substantial break-through with the claim that "something's work sometimes if the treatment is appropriate", considering that the treatment was deemed "appropriate" if it worked.

\section{Charles H. Logan and Gerald G. Gaes} Meta-Analysis and the Rehabilitation of Punishment

Logan and Gaes (1993) offer a critical stance on the methodology of a metaanalysis, specifically meta-analysis that have examined rehabilitation in the correctional system. Logan and Gaes are proponents for a "confinement model" of imprisonment "which rejects rehabilitation as an official goal and yet allows for programs of work, education, and other activities within the mission of a prison (Logan and Gaes 1993:245)." Ultimately, they build their argument by punching holes in prior metaanalytic techniques, and argue a stance firmly rooted in a deterrence theory based, punishment oriented model of justice. 
Empirical research and ideology have both played a role in the debate over "treatment versus punishment", a role that must be examined by the researchers. The ideology supporting rehabilitation gained momentum as the social sciences developed in the thirties and forties. Rehabilitation seemed to crown in the fifties as the medical model reached its peak. As many people lost faith in rehabilitation during the sixties and seventies, it had nearly vanished by the eighties. However, through the engagement of a new methodology called meta-analysis, the nineties seem to have found a new embrace for rehabilitative ideology (Logan and Gaes 1993:245).

Throughout the article, they often cite the shortcomings of prior meta-analyses examining treatment versus punishment, and then follow it with a judgment call on how the correctional system should be rooted in a punishment oriented philosophy rather than a rehabilitative one. They do point out several issues to consider when utilizing the metaanalytic method, such as the introduction of controls and outside variables. They descriptively warn how such measures are often used to promote the researcher's agenda. Variables that are introduced can often allow the research to make claims that on the surface seem to be substantial breakthroughs in the field, but when examined closer show flawed research methods, or tautological reasoning (Logan and Gaes 1993:253).

Logan and Gaes utilize a brief explanation of how the labeling theory has guided the public's view of the correctional system. They identify the transition of the label from the "penal" system to the "correctional" system, stating that this label "reinforces a false hierarchy of values in which 'helping' is seen as superior to sanctioning (Logan and Gaes 1993:253)." The adoption of this new language refers to a justice system in which treatment is the predominant goal. Logan and Gaes argue that the language of treatment is 
one already utilized by the medical, psychological, and educational communities, and they believe that the justice system is seeking to substantiate its legitimacy and achieve a level of prestige comparable to those other systems.

Logan and Gaes identify how the label of our justice system causes different reactions and definitions of the situation. Proponents of the treatment philosophy claim to take the moral high ground by constructing a benevolent and humane correctional system where inmates are rehabilitated and are no longer criminals upon their release. The proponents of the confinement and punishment oriented model of justice are often on the defensive as they are faced with the stereotypical perceptions of "warehousing criminals," or "caging" of inmates with cruel and inhumane conditions within their prisons. Logan and Gaes go on to cite Garland's 1990 work "Punishment and Modern Society" in support of their punishment-oriented ideology. Garland regards punishment as a significant aspect of culture, which can build on Durkhiem's (1897) claims that crime is a normal function of society. If crime is a normal or necessary function of society, then we can begin to understand how punishment can be a symbol, or an expression of cultural and moral values passed down by the dominant culture. Punishment itself can construct and communicate, effectively, some of the most important shared meanings, values, and beliefs that define a culture.

In closing their argument, Logan and Gaes state that it is the prison's duty to govern fairly and well within their own walls, but it is not their duty to reform, rehabilitate, or reintegrate offenders into society. "Though they may attempt these things, it is not their duty even to attempt these goals let alone their obligation to achieve them. Prisons ought not to impose upon themselves, by inclusion in a mission statement, any 
responsibility for inmates' future conduct, welfare, or social adjustment (Logan and Gaes 1993:261)."

\section{Frank S. Pearson and Douglas S. Lipton}

A Meta-Analytic Review of the Effectiveness of Corrections-Based Treatments for Drug Abuse

Frank Pearson and Douglas Lipton (1999) did not directly enter into the ongoing argument within the literature of treatment vs. punishment, but did contribute a significant revision within the meta-analytic methods that were guiding the arguments in the literature. Pearson and Lipton stressed the necessity of subdividing treatment modalities in order to provide insight into what specific programs are working and which ones are not. They also incorporated a control for the quality of meta-analytic results provided by each study. This new criteria of inclusion for their meta-analysis narrowed the focus of the study to a more specific type of rehabilitation. The new criteria for inclusion searched international literature only on substance abuse treatment, was published or unpublished from 1968 until the end of 1996, which focused only on adult offenders and gave descriptions of treatment modalities within the study. Their search results allowed for treatment to be categorized into three modalities: boot camps, therapeutic communities (TCs), and group-counseling programs focused on substance abuse.

Pearson and Lipton's study determined there was no significant evidence to show that boot camps or group counseling are effective at reducing recidivism. They did, however, find that Therapeutic Communities show a significant reduction in recidivism. They also found that methadone treatments and 12 step programs showed promising 
evidence of success. Yet, neither had enough research to provide an accurate conclusion of their effectiveness.

\section{Duren Banks and Denise C. Gottfredson}

The Effects of Drug Treatment and Supervision on Time to Rearrest Among Drug Treatment Court Participants

Banks and Gottfredson (2003) identified the concept of Drug Courts,

implemented by several justice systems throughout the United States. They identify and point out the key elements of drug courts and how they directly impact the research question of "What Works?" They do so by incorporating exactly what advocates of the treatment philosophy have claimed works. The specifics of many drug courts operate differently depending on the jurisdiction they are located in, but all of them operate within the same ideology by removing drug offenders from the punishment-oriented system and creating a whole new system where they can be treated or rehabilitated while remaining under the supervision of the justice system through a type of nonincarceration-based supervision.

Banks and Gottfredson's research focuses on drug court participants comparing four groups; a control group, a group presented with just drug treatment and no supervision, a group with supervision but no drug treatment, and a group that had drug treatment and supervision. They also decided to utilize different measures rather than the classic outcome of "which one produces the lowest recidivism". Banks and Gottfredson decided to measure not only whether participants were rearrested but also the length of time until their rearrest.

Banks and Gottfredson found that individuals who received treatment and supervision had the longest time until rearrest, but not significantly longer than those who 
received only treatment. The individuals who received only supervision did not differ significantly from the control group. They also discovered that the length of time since an individual had been in treatment directly affected their risk of rearrest.

While Banks and Gottfredson did not directly look at incarceration-based drug treatment, they still maintain their place among the ongoing argument in the literature by providing these new insights of seeing if treatment is effecting not whether an offender is rearrested, but how long till they are rearrested.

\section{Ojmarrh Mitchell, David B. Wilson, and Doris L. MacKenzie Does Incarceration-Based Drug Treatment Reduce Recidivism? A Meta-Analytic Synthesis of the Research \\ Mitchell, Wilson, and MacKenzie (2007), provide us with the most up-to-date,} methodologically sound meta-analysis of incarceration-based treatment's effect on recidivism. While their eligibility for the criteria of inclusion is inconsistent, they do provide a good outline of meta-analytic methodology for this type of research.

The researchers' meta-analysis included any studies they found through library, internet, and database searches that consisted of, published or unpublished, experimental or quasi-experimental, evaluated any incarceration-based drug treatment program, examined juveniles or adults, contained a control or comparison group, completed between 1980 and 2004, and they must have provided enough information to calculate an effect size. All studies included also had to impose a measure of post-release recidivism, but studies examining halfway houses and community-based residential facilities were dropped from the analysis. Their unit of analysis is the evaluation, a contrast between one treatment group and one comparison group. While they combine juvenile and adult data along with including studies from non-published sources, they manage to examine the 
data in a methodologically sound way, by introducing a variable to measure the quality of each study.

Mitchell, Wilson, and MacKenzie also categorize the treatment types into therapeutic communities, individual counseling, group counseling, boot camp/shock incarceration, methadone maintenance, multiple modes of treatment, and other. This is an important sub-categorization of the treatment types, so the measure of a boot camp's effectiveness is not being affected by the outcome of a therapeutic community's effectiveness. They then utilized the odds ratio of the dichotomous outcomes to identify effect size, as outlined by Lipsey and Wilson (2001). They also introduced a method to control selection bias by combining failures or dropouts with the graduates, and recalculated recidivism rates for the whole group. These recidivism rates were then compared to the control group to calculate an effect size. This method, they stated, would reduce the likelihood of a selection bias in the end results of their meta-analysis.

Their initial search returned 233 potential studies, 53 of which met the criteria of inclusion. Of the 53 studies they found, 66 independent evaluations were included, as some studies contained multiple evaluations. Of the 66 evaluations, 30 had looked at TC (therapeutic communities), 25 looked at counseling programs, 5 examined narcotic maintenance programs, 2 evaluated boot camps, and four could not be reliably coded. The outcome variables were coded in terms of re-offending and drug use as a measure of recidivism, and no re-entry into the justice system or no further reported drug use as nonrecidivism.

The reported findings for each sub-category of treatment varied in its success to reduce recidivism. Boot camps, while relying on a relatively low number of evaluations, 
were found to have no reduction effect on recidivism. Drug maintenance programs actually produced higher re-offending rates than those in their comparison groups. However, the authors felt it important to point out that the evaluations measuring postrelease drug use provided promising data to support a reduction in drug use, but not reoffending. The TC's provided the most evidence of reducing offending and drug use, consistently having lower rates of recidivism. This finding was robust across methodological variation and quality of study, although selection bias was controlled for; the authors pointed out that this modality carried the largest selection bias in the original literature. Of the 30 TC evaluations, 10 examined Residential Substance Abuse Treatment (RSAT, a federally funded and regulated treatment program) funded programs. The RSAT programs significantly decreased re-offending, but only had a 50/50 chance at reducing drug use. The counseling treatment programs were shown to reduce re-offending, but the original evaluations did not contain enough data to evaluate their effect on drug use.

Two interesting findings were interpreted from this data. First, treatment programs applied to women were found to be more effective across the board. Second, they found the TCs and counseling programs to have a greater effect on reducing re-offending rates than on drug-relapse measures. This finding brings the underlying presumption of the effectiveness of these programs to question. In fact, reductions in re-offending may not actually be mediated by a reduction of drug use (Mitchell, Wilson, and MacKenzie 2007:370). Altogether, the authors decided TCs show the most promising reductions on re-offending and drug use, but further quality research is needed in these areas, as they found what is available to be methodologically weak allowing itself to be open to alternative explanations. 


\section{THEORETICAL FRAMEWORK}

\section{Labeling Theory}

Labeling theory, a derivative from symbolic interactionism, gained heavy support during the mid-1960's; however, its essential core argument dates back to Alfred Lindesmith's work in 1947. Lindesmith had hypothesized that opiate addicts were not seeking the euphoric effects of the drugs (he minimized the focus of the effects of drugs), but they continued using, because through interactions with one another, addicts believed they could not successfully complete withdrawal and live. This led to Lindesmith's assumption that defining oneself as an addict was the pivotal moment in an opiate user's life. He argued that anyone who underwent medical treatment for addiction but denied the label of an addict could successfully break the bonds of their addiction. However, those who accepted the label of addict would, through interactions with other self-defined addicts, come to accept their state of being and regard withdrawal as impossible (Best 2004:6).

Labeling theory, when initially examined, seems to be a simple concept. Labeling theory coincides with social reaction theory, and often credits Howard Becker as being the original founder of the labeling theory. Upon closer examination, the labeling theory is very extensive and has seemed to weave its way in and out of other theories.

The labeling theory proposes that any act is a socially constructed reality and not necessarily a behavioral fact. Following the act, a societal interpretation occurs, and a reaction is formed based on a society's perceived norms. This reaction is an attitudinal 
assessment of the actor and serves as a "yardstick of morality, disruptive potential, and mental pathology" (Meade 1974:84). Labeling theory advises that this societal reaction to the act will have an influence on the psychic state of the actor. The actor internalizes the reaction and negotiates a subjective response. The intensity of the actor's commitment to and internalization of this reaction designates his or her acceptance or denial of the label created by the societal reaction. In the final stage of the labeling theory, an act of secondary deviance occurs as a result of the acceptance, forced acceptance, or identification with the label (Meade 1974).

There are two focus areas of the theory that borrow from other theories. The first, which borrows from symbolic interactionism and conflict theory, is that no action is inherently evil until it is labeled so. In support of this, labeling theorists assume that nothing was originally illegal until it was labeled as illegal. The flaw with this occurs as the theorists encounter a problem in defining deviance; this train of thought presumes that deviance and illegal acts are synonymous with one another. Many examples of this have been identified by labeling theorists who have examined the labeling inherent in a number of types of deviance. Witches, as an example, go to show that a woman labeled as a witch cannot be done so based on any physical proof or actual behavior, since magic does not actually exist. However, the label is still applied, regardless of the absence of an act. This further exemplifies that labels need not actually be linked to a behavior (Best 2004:22-23). "Mental illness, because it illustrates uncertainty in defining deviance and applying labels (since identification and classification has exhibited fluidity throughout the decades, i.e. homosexuality). Crimes without victims, (i.e. sexual exchanges and drug deals) because they expose conflict between officals' and participants' definitions of 
deviance" (Best 2004:23). We could go a step further into developments of the theory to say that defining the act as deviant can be attributed to the conflict between those doing the action and those regulating the actions, as the latter are able to impose their values and beliefs upon the former by labeling the actors as deviant and carrying out sanctions.

The second area does not draw as heavily on conflict theory, but rather focuses on social-psychology while still incorporating symbolic interactionist views, and borrows ideas from Goffman, Tannenbaum, and Cooley. It describes and identifies the effects that a societal reaction has on the individual's definition of themselves, and the self-fulfilling prophecy that drives the secondary deviance. The first step of the theory is the primary deviant act that leads to the social reaction (a label). This primary deviance has been examined by Joel Best, as he states;

On one hand, they (labeling theorist) seemed to argue that primary deviance was irrelevant, in that it did not matter what the person who had been labeled might have done, only the deviant label that had been applied. Labeling theorist were fond of extreme examples, such as witchcraft and other offenses that did not exist in reality yet for which labels might be applied, or cases of labeling that seemed to involve capricious decisions on the part of social-control agents. By focusing on such examples, labeling theorists could make the case that primary deviation was irrelevant; conceivably, labels might be handed out randomly (2004:22).

Erving Goffman published Stigma in 1963, where he outlines how people with different identities can have "spoiled identities" in which they feel other people's reactions will be negative, or view them as flawed somehow. Goffman focused on individuals with handicaps (such as blindness), but said in response to this, the individual will seek to manage or cope with the stigma attached to their identity. Goffman provides an example of how one can become exposed to stigma. People who are discredited (those whose flaws are known) will experience the full stigma, while those who are 
discreditable (whose flaws are not yet known) may be able to avoid stigma (Best 2004:16).

Next the discredited individual will encounter two types of societal reactions. The first is the formal objective societal reaction, and the second is the informal subjective societal reaction (Meade 1974:84). Formal objective societal reactions are events such as court hearings, interventions, and prison sentences. The informal subjective societal reactions are moral violations with informal sanctions such as parental punishment or dissociation.

From these societal reactions, labels are formed. Becker mentioned that societies create deviance by their reactions to different acts. From this reaction "a name, definition, or label designates something which is the product of a successful conversation of gestures" (Melossi 1985:199). It is the success of the conversation of gestures that makes it possible to label the "self." Labeling theorists assume that, during real or imagined interactions, individuals project themselves into the role of the significant others and make assessments or self-appraisals (Cooley 1902). The self is then able to become an object of examination, from which the individual derives a label, either negative or positive (Mead 1934). This assumption posits "that humans have the ability to choose among competing labels for their self-conceptions.” (Adams 2003:173)

Upon being confronted with the label, it is the individual's decision to negotiate the label with his or her "self." There can be three different outcomes from this negotiation. An individual can accept the label, deny it, or the individual can attempt to deny the label yet be forced to accept it. If an individual can successfully deny the label, then he or she is likely to not have a stage of secondary deviance, according to the 
labeling theory. An individual who attempts to deny the label but is forced to accept it will be likely to have an act of secondary deviance. This can occur in cases such as: the Salem witch trials, felons who try to get a job, or convicts trying to obtain financial aid in order to go to college. A woman who is accused of being a witch can deny the label to the fullest of her abilities, but regardless of her self-concept, if she doesn't drown (drowning was a test used during the Salem Witch Trials to tell whether someone was a witch, as it was believed that witches could not be drown), then that is secondary deviance only reifying the label further, for this she will be sanctioned to burn at the stake! Lastly, the theory proposes that if the self-appraisal accepts the label and is strong enough, an individual will then create a "Self-Fulfilling Prophecy."

The labeling theory now adds to its ever growing "borrowed" ideas Robert Merton's concept of the "Self-Fulfilling Prophecy." Merton tells us that "in the beginning, a false definition of the situation (Label) evokes a new behavior which makes the originally false conception come true. [It] perpetuates a reign of error" (Merton, 1968). It is within this "Self-Fulfilling Prophecy" that some labeling theorists impose the presence of Edward Sutherland's differential association theory. Bernburg, Krohn, and Rivera (2006:81) provide empirical evidence that lends "support to the idea that official labeling triggers processes that increase involvement in deviant groups.” Prior research shows that during adolescence, a formal label maybe consequential for one's life course. By being labeled, a youth may have structured opportunities and legitimate means blocked and subsequently suffer dissociation from non-deviant peers. This would lend them to associating with other deviant youth or performing secondary deviant acts (Bernburg et al. 2006:83). 
Figure 1: LABELING THEORY

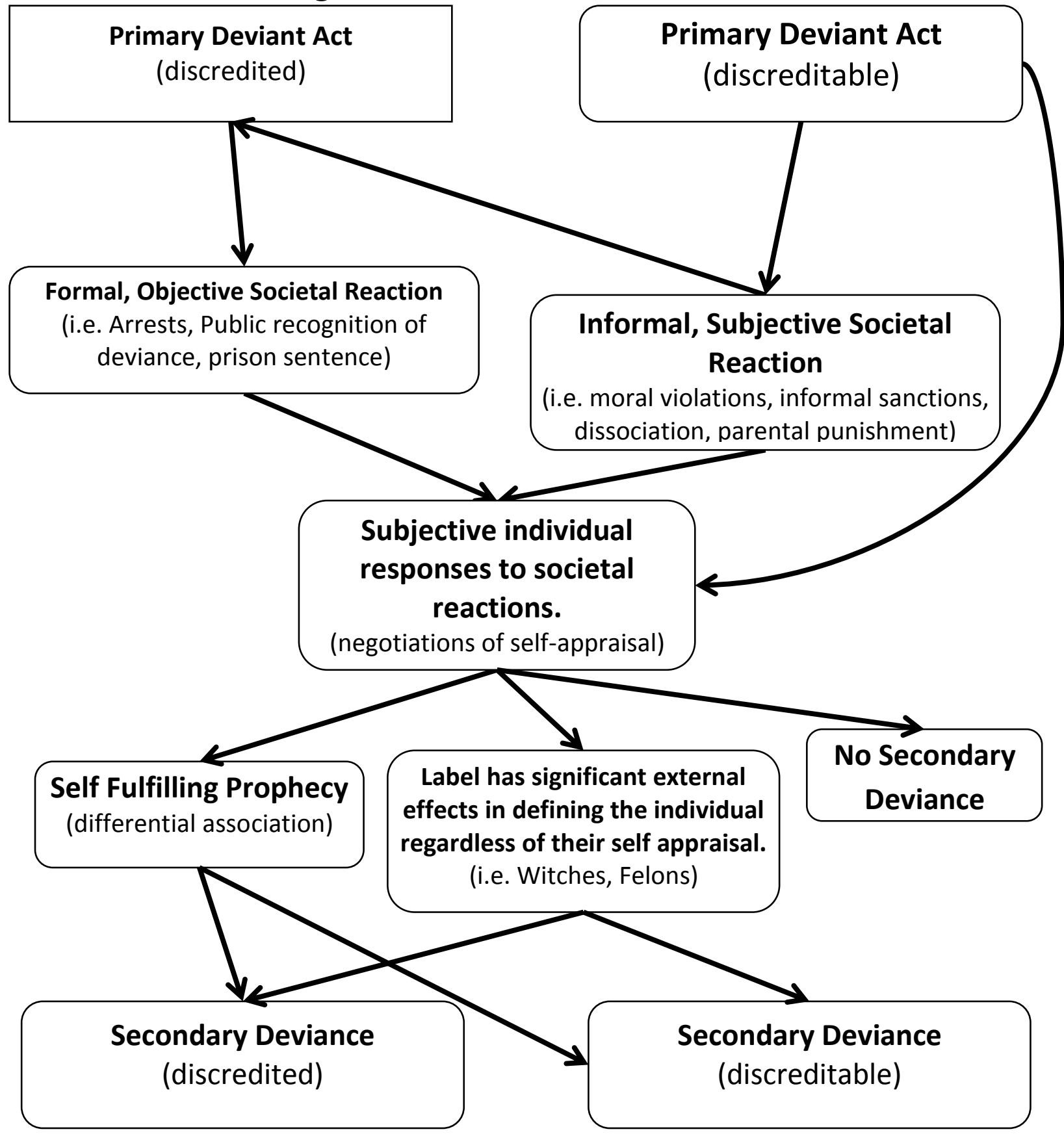


Labeling theory has its share of criticisms from several other schools of thought. One (of its most critical) is its heavy dependence on the term deviant. Deviance is a difficult term to define due to the fact it is based on societal reactions. Durkhiem was able to blend deviance into his theories successfully by arguing that deviance will perpetually exist as long as society does. Durkhiem explained that deviance was dependent on the Conscious Collective of any society, as it was the Conscious Collective that defined what is deviant and alternatively what is sacred.

When asked whether some behavior, for example, standing in an elevator and facing the back wall instead of the door, is deviant, sociologists often hedge. "It might be deviant," they say, "It depends." But on what does it depend? The sociologist begin to squirm: "Well, it all depends on how people react." That is, if other people become upset by the behavior, then we might consider the behavior deviant (Best 2004:15).

By viewing deviance in such a way, labeling theorists were able to reframe the mainstream questions surrounding deviance. Instead of asking "What causes individuals to commit deviant acts?" sociologists now asked "What causes some acts to draw sanctions, to be labeled as deviant?" It was by doing this that labeling theory met its next criticism. Some sociologists, according to Best (2004), claim that the term "Labeling Theory" was far too grand in that it didn't really create a formal theory or cause the development of a single unified school (e.g. Chicago School, Frankfurt School, etc.). The term instead referred to a flooding of intellectual activity that focused on defining deviance through societal reactions (Best 2004).

However, while credited with provoking a new way of looking at deviance, it still carried the burden of being able to define deviance. One such example is that of intelligence tests scores in which scores are generally distributed in a bell curve, with 
most of the scores falling in the middle, but a few extremes on both sides of the curve usually occur. However, if we draw on statistical terms, "to deviate" refers to those who score outside of measures of central tendency, most commonly one or two standard deviations above or below the mean. Throughout history, those who have scored on the low side of the curve have been considered retarded or mentally handicapped, and thus labeled deviant. But what of those who score on the extreme positive side of the test scores? Would they also be considered deviant? The student who deviates on the positive side of the test scores is likely to undergo stigma (being labeled as a "nerd") just as the child who is considered retarded experiences stigma. So can deviants be too bright, too brave, too well adjusted? (Goode 1991).

In addressing this problem of whom to include in deviant categories, theorists also have to be cautious of definitional creep. By net widening the term deviant, it needs to remain something in which the minority of us participates. From a statistical point of view, the term needs to remain adherent to a small proportion of the population. If it becomes too inclusive, then it simply becomes another term for humans and possesses no theoretical or statistical significance (Best 2004).

Since the labeling theory seems to draw upon several different theories, it has received criticisms from each specific school of thought. The conflict theorists claim that it does identify a power struggle between classes by creating reactions to people's actions then applying stigmatizing labels. However, conflict theorists (Gouldner 1968:112; Thio 1973; Liazos 1972:116) criticize labeling theory, saying it is too complacent for buying into the existing social order and does not questioning the struggles between the working class and the economic elites. Feminists (Brownmiller 1975:5) claim that the labeling 
theory neglected the patriarchal system that subjugated women's lives and offered no protection to them against victimization (Best 2004:49). Political activists made the claim that in regards to gay liberation, and disability rights, the struggles in their lives are better determined through terms of politics rather than deviance (Humphreys 1972; Warren 1974). Lastly, mainstream sociology critiqued the theory for its underlying assumptions, stating that the definition of deviance was highly inaccurate, difficult to measure, and the predictions it made were simply wrong (Best 2004:49).

The last attack by mainstream sociology produced large sums of data supporting the inaccuracies of the labeling theory. For example one study that highly discredited the theory was done by McAuliffe and Gordon (1974). McAuliffe and Gordon went back to the theory's foundation, Lindesmith's 1947 theory of opiate addiction, and decided to complete a similar study in order to test the reliability of the original study. In their interviews with 64 addicts, they found that addicts reported the euphoric effects of the drugs as their main reasons of use. While this study did not, on the surface, directly discredit the key ideas of the labeling theory, it did raise a good point. If Lindesmith simply misunderstood the motives of his opiate addicts, then his entire theoretical explanation may be flawed. "If the principal finding of a classic qualitative study, certainly considered an exemplar by Howard Becker and other labeling theorists, was wrong, how much confidence should sociologists place in labeling's findings, which were almost always derived through such methods?" (Best 2004:46).

The time order of not only the theory, but also its critiques, must be examined in context for a true understanding of its success and failure. As the theory developed and became popular in the 1960s, it is easy to see why it gained so much support. The theory 
had risen to its prominence in a time of rebellion, activism, and questioning of authorities, which in turn is what the theory essentially argues. Many proponents of the theory suggested that social control was less than perfectly evenhanded (Best 2004). In the 1960s many people were looking for ways to show their government's faults, and a theory such as labeling gave them the theoretical stepping stone needed to further their causes. Even if this assumption of social control not being fairly delegated was true, empirical evidence from the 1970 's "indicated that social control was not nearly as arbitrary as labeling theory had implied" (Best 2004:48). In the 1960s, it was the highly publicized youth that argued they were being suppressed by a minority of powerful political elites, when in reality it was the youth who were in the minority and the general public's ideology was actually in line with the "political elites."

Following the period of critiques on the labeling theory, many sociologists took the stance that, "Although labeling's focus on societal reaction had offered some new ideas, they did not all, in turn, inspire further developments. Some concepts proved to be theoretical dead ends" (Best 2004:59). The criticism of tautology was applied easily to the labeling theory. In asking what caused a person to be deviant, theorist would reply "their labels," then asked what prompted the application of a label, the theorist would reverse the explanation, saying "people are labeled because they are deviant." So are they deviant because they are labeled, or are they labeled because they are already deviant? Which came first the chicken or the egg? In response, by classifying the two categories of deviance (primary and secondary), theorists corrected this, yet since the theorists ignored the cause of primary deviance, this led to another set of problems. 
As the technology rapidly developed in the1970s, researchers had new statistical tests and instruments that could be run relatively easily and inexpensively. This provided the means to quantitatively evaluate the concepts of the theory. Sociologists examined the process by which social control agencies operate and deal with deviants. But defining deviance was still under attack (Gouldner 1968; Schervish 1973; Thio 1973; Liazos 1972).

By the late 1970s, many of the labeling theorists had moved away from studying deviance, but several new forms of thought would soon come from the roots of the labeling theory. One of the biggest proponents of labeling was the social constructionist perspective. Social constructionists focused on the creation of labels by society as a central aspect to studying social problems. Constructionism drew attention to how society, the media, and policy makers defined social problems. They also examined how the public comes to adopt these views and recognize the problems in certain ways. "Rule creation had been one of the original emphases of the labeling approach, and it was in many ways the portion of labeling theory that had been least damaged by the various critiques labeling had experienced" (Best 2004:58).

Labeling had also made its mark in explaining recidivism rates among prisoners. One of the most relevant elements that emerged within this field was based on the labeling theory. "Since the labeling theory argued that people became deviant - or at least committed to deviance - through labeling, then perhaps some sort of relabeling might be the key to understanding why people stop being deviant" (Best 2004:61). This can be seen as drug users are slowly being relabeled from criminals who need to be punished to addicts who need help. 
This relabeling idea may be more difficult for some deviants than others. Deviants who have had their labels institutionally reinforced may have a difficult time projecting their "new labels." This is the case with felons; while technically they are supposed to be "rehabilitated" upon their release from prison, many times this label is overridden by the "felon" label. Felons or ex-cons are a prime example of how a label can promote a string of secondary deviant acts. Through a systematic reaction to their label they constantly encounter blocked means (Richards and Ross 2003). Examples of this are the restriction of financial aid to felons and the requirement to inform potential employers of their prior convictions. The most extreme examples come from that of sex offenders and the constant increase of post-release regulations such as sex offender registries. However, when making such claims, one must examine any underlying assumptions in regards to the felon's blocked means. By this, I mean before making such claims, one must examine whether or not the label actually blocks any legitimate means that would have not been normally blocked to a "non-con."

If a drug offender were to be considered a patient in the medical realm, rather than a criminal by the penal system, could the offender's label allow for a more successful reintegration into society following treatment? If the label of felon were removed and the stigma attached to that label ceased to exist, the offender could take on the identity of the patient rather than sustain the characteristics of the felon. The biggest effect this relabeling could have on the patient would be at the stage of the theory following the patient's Self-Appraisal. This stage seems to be the pivotal moment where the presence of secondary deviance will be determined. In accordance with the labeling theory, this patient identity would not only provide access to legitimate means for the 
patient, but could also address the issue of dissociation from quality peer groups. Since it is not criminal to have a medical problem, the patient may have more access to positive influential peer groups. For example, they may obtain a better job than a felon could, resulting in association with co-workers from higher socioeconomic and educational backgrounds. By the offender carrying the label of patient over felon, this would also lower the ability of the label to create significant external effects denying the offenders self-appraisal; instead, it may lend itself to creating external effects that encourage the offender to abstain from future deviances through the use of positive peer-groups. Lastly, if the failure of the offender is inevitable, than the secondary deviance itself carries a sort of relabeling that lends itself more to the rehabilitative model than the criminal one. When a drug offender treated in the medical realm is clean but returns to drug use, we label this as an incident of relapse, whereas the justice system sees it as recidivism.

Now, with respect to this study, we can see the importance of proper labeling and distinction between offender groups. While sex crimes, drug offenses, and other victimless crimes are illegal, it is important they be labeled and treated separate from heinous crimes such as murder. If not, we are grouping all different types of people, actions, and treatments into one convoluted label that we can expect to follow and define these individuals for a long time to come. 


\section{RESEARCH METHODOLOGY}

\section{Meta-Analysis}

A meta-analysis, or sometimes referred to as a quantitative research synthesis, is a statistical method used to provide a summary of the findings of multiple independent research studies on the same topic. While a meta-analysis can integrate the findings of as few as two studies, it can also "look at the bigger picture" of hundreds of studies. Metaanalytic methodology is an extremely effective tool when there are many studies available, all examining the same social phenomenon. Often this methodology is criticized by the common misconception that meta-analyses combine many different kinds of studies of different quality, essentially comparing apples to oranges. However, a meta-analysis of good quality will control for these differences through a stringent criteria of inclusion, eliminating the oranges and comparing apples to apples. For the meta-analysis to be effective, studies must (1) deal with the same constructs and relationships and (2) be configured in the same statistical format. It is important to note that a meta-analysis should be understood as a "form of survey research in which research reports, rather than people, are surveyed" (Lipsey and Wilson 2001:1).

The steps in the meta-analytic methodology, according to Lipsey and Wilson (2001), are as follows;

1. A research question is formed

2. A search for all potentially relevant primary research studies is completed

3. "Fair, relevant criteria are applied to maximize the inclusion of relevant primary research studies and to minimize the inclusion of studies that are not truly relevant to the research problem formulated" (Lipsey 1999:388). 
4. A coding form, or survey protocol is developed to identify explanatory variables, outcome variables, and moderator variables

5. Once a population of research reports are gathered, each research study is "interviewed" by the researcher who codes the appropriate information from it.

6. An effect size is calculated for each primary research study based on the outcome variables.

7. The resulting data is then analyzed using special adaptations of conventional statistical techniques to describe the distribution of effect sizes and make statistical inferences.

8. Furthermore, a researcher can use statistical methods to ascertain the degree to which the relationship between the independent variable and outcome variable depend on the values of a moderator variable.

\section{A Research Question is Formed}

The literature seems to show inconsistency in regards to the effectiveness of rehabilitation in an incarceration-based setting. Martinson (1974) claims nothing works, then recants his findings (1979) stating that something's work sometimes with certain populations. Gendreau and Ross (1987) find that some forms of rehabilitation do work with certain populations but caution administering these specific forms of treatment to general populations until further research is available. Andrews et. al. (1990) find rehabilitation works if treatment is appropriate. Logan and Gaes (1993) claim prior metaanalytic studies were flawed, biased, and their results should not be trusted. Instead Logan and Gaes (1993) claim whether rehabilitation is effective or not, it does not belong in a prison where the focus should be punishment oriented. Pearson and Lipton (1999) address some of the methodological problems with former research and separate the different types of rehabilitation to examine them and find that TCs show significant reductions in recidivism. Mitchell, Wilson, and MacKenzie (2007) provide a metaanalysis utilizing the current standards and find the TCs seem to work, however they meet the criticism of having a scattered criteria of inclusion. 
As illustrated by the literature, some researchers claim incarceration-based rehabilitation is effective (Andrews et. al. 1990, Pearson and Lipton 1999, Mitchell, Wilson, MacKenzie 2007). Other researchers claim we simply cannot know the level of effectiveness due to the flawed methodology of prior meta-analytic research combined with the lack of available research altogether (Gendreau and Ross 1987, Logan and Gaes 1993). While many researchers take Martinson's (1979) position in claiming that sometimes, with some populations, somethings work. One thing most prior meta-analysis agree on, is that more research in this field is required (Gendreau and Ross 1987, Martinson 1979, Pearson and Lipton 1999, Mitchell, Wilson, and MacKenzie 2007) In the early 2000's a group of criminologists (Austin 2001, Mauer 2006, Richards and Ross 2002) began criticizing such meta-analysis for their inaccuracy stating that prior studies on rehabilitation had combined data from different populations, eras, locations, and justice systems to arrive at their results. These criminologists seem to support the rehabilitative model, although they caution against the methodology utilized by metaanalysis. Specifically they introduce a new ideology in regards to the inmate's motivation for participating in the rehabilitative programs. Austin (2001) claims studies mixing data from determinate and indeterminate sentencing eras are ignoring the possibility of inmates simply participating in programs solely for the time reductions instead of selfbetterment (Austin 2001:92). I seek to address these criticisms and bridge the gap in the literature by isolating the motivational factor of participation solely for time reductions. I do this by only examining studies from the determinate sentencing era where it is believed inmates would participate in such programs only for self-betterment rather than large time reductions (Austin 2001, Mauer 2006). 
Using rigorous meta-analytic methodology, I seek to examine incarceration-based drug rehabilitation programs and their effectiveness at reducing recidivism during the determinate sentencing era. I have acknowledged the warnings of prior researchers, and seek to form a stringent criterion of inclusion to make my meta-analysis stand out as a methodologically sound study. I hypothesize that incarceration-based rehabilitation during the era of determinate sentencing will reduce recidivism.

\section{The Search}

An initial search for studies was conducted utilizing University of Louisville's access to computerized databases across multiple terms related to incarceration-based drug rehabilitation. Databases searched included: EBSCO Academic search premier, Social Sciences Index, Sociological Abstracts, Applied Social Sciences Index and Abstracts, Criminal Justice Abstracts, CINAHL, and NCJRS (National Criminal Justice Reference Service). Terms were searched in each database and results were recorded for relevant research studies that met the criteria of inclusion. Many of the same studies were repeated across multiple databases; this was noted and subsequent appearances of studies already found were disregarded. Terms searched included the following: prison rehabilitation, incarceration-based rehabilitation, drug rehabilitation, prison drug treatment, incarceration-based drug treatment, residential substance abuse treatment, prison substance abuse treatment, incarceration-based substance abuse treatment, RSAT evaluation, RSAT programs, prison therapeutic communities, incarceration based therapeutic communities, Prison Counseling, incarceration based counseling, prison 12step, and incarceration based 12-step. 
Twenty-four relevant studies were presented by the initial database search. The EBSCO Academic Search Premier database search under the term "incarceration based rehabilitation" presented the most with 11 studies. Upon closer examination, 12 studies were eliminated due to their inability to meet the stringent requirements of my criteria of inclusion. Eight of these studies were dismissed due to the lack of containing a comparison group. Another 3 were dismissed because they were international studies, and 1 due to the fact its comparison group was composed of juveniles. Only 12 of the 24 studies met the complete list of criteria of inclusion.

\section{Inclusion Criteria and Scope of Study}

The scope of this study is scholarly or peer-reviewed publications along with government documents that have utilized a behavioral/social science research methodology, which may include experimental or quasi-experimental research structures. Eligibility criteria for this meta-analysis were that: (1) studies must contain 2 groups, a group that has undergone a form of rehabilitation or drug treatment, and a group of comparison that has not underwent rehabilitation or drug treatment; (2) Drug treatment or rehabilitation must have been administered in a United States' correctional facility (Prison, federal or state, as well as jails); (3)The treatment program and its evaluation must have taken place between 1985-2010; (4) Studies must focus on adult populations, but may possess males or females; (5)The evaluation of the groups must report an outcome variable of recidivism; (6) Studies must define the specific type of rehabilitation (drug counseling, therapeutic community, 12-step, ect.). Only studies examining Therapeutic Communities or counseling will be used. This is due to the lack of objective 
literature on boot camps and drug maintenance programs (especially ones that adhere to criteria 4) (Mitchel, Wilson, and MacKenzie 2007:369).

In regards to the first eligibility criteria that studies must contain a treatment group and a comparison group, the comparison group is compared to that of a control group who did not receive any treatment or what some researchers deemed "treatment as usual". For purposes of this analysis, we consider the terminology of comparison group and control group as analogous and interchangeable. "Treatment as usual" in some correctional settings may mean that while the inmates did not receive the drug treatment that was being examined, they may have still met with correctional counselors or participated in some type of treatment that is considered by that institution as part of the daily regimen for the general population of the facility. In these cases, the treatment groups underwent the same daily regimen as the control but in addition had extra treatment sessions with counselors or lived in one of the facilities Therapeutic Communities. This meta-analysis disregards studies that only contain treatment to treatment comparisons, as these studies examine different types of treatments for effectiveness yet do not contain control groups. I also disregard "time in treatment relative to recidivism" studies, as these do not contain control or comparison groups.

Criterion 2, 3, and 4 differentiate this analysis from others before it by striving to make a more accurate comparison of "apples to apples". The geographic restriction allows for a more uniform treatment and outcome variable by eliminating disparities in international legislation as well as varying philosophies on treatment from nation to nation. The time constraint seeks to eliminate the comparison of rehabilitation under indeterminate sentencing to rehabilitation under determinate sentencing as criticized by 
Austin (2001) and Mauer (2006). While the end of indeterminate sentencing is hard to pinpoint, the Bureau of Justice Statistics recognizes the enactment of Truth in Sentencing and mandatory minimums as the end of the indeterminate sentencing era. Since Truth in Sentencing now states that offenders are to serve a minimum percentage of their original sentence, offenders no longer entered the correctional system having no idea when they would be released. According to the Bureau of Justice Statistics special report on Truth in Sentencing in State Prisons (1999), Truth in Sentencing was officially enacted in 1984 and most states quickly adopted it with federal grant money on the line. Since legislation takes time to be implemented, we accept 1985 as the beginning of the determinate sentencing era. There are many disparities between the juvenile justice system and the adult justice system, thus they are two separate justice systems and should be treated as such. That is exactly what is done by excluding any data that focus on or make comparison of a juvenile treatment program.

Criterion 5 states that the study must contain an outcome variable of recidivism. Under close scrutiny, the variable of recidivism becomes a controversial unit of measure and often the definition of recidivism varies from study to study. In order to identify the operational definition of recidivism for the purposes of this study, the recidivism variable is inclusive of any re-entry into the criminal justice system. This can be parole revocation, re-arrest, or re-incarceration (Pearson \& Lipton 1999:391).

Criterion 6 focuses on the type of treatment or rehabilitation the treatment group receives. Pearson and Lipton's (1999:387) definitions of Therapeutic Communities and counseling programs will be accepted for the purposes of this study. 
Counseling programs (other than TC's) often vary from facility to facility, and within the studies that examine the effectiveness of counseling, counseling interventions are often vague and just briefly described. Most counseling programs contain a group component if not entirely group based. While some use tier-stepped approaches, introducing the inmate to the program with substance abuse education then slowly moving them into milieu therapy, alternative coping skills, behavioral skills counseling, teaching positive alternatives, and offering guidance on lifestyle choices, as well as case management, others simply consist of daily group therapy focusing on chemical dependency and substance abuse. For this study I will include any type of counseling that inmates participate in beyond that of "treatment as usual".

\section{4 \& 5 Coding Forms and Interviewing the Studies}

A coding form was created to extract and record variables from each study as it was interviewed and raw data was pulled from its contents. Variables were coded for the following: 


\section{Chart 1: Coding Variables}

\begin{tabular}{|l|l|}
\hline VARIABLE & Description \\
\hline StudyID & Study identification number \\
\hline PubType & Publication type \\
\hline PubYear & Publication year \\
\hline TreatType & Primary treatment type \\
\hline TreatSetting & Social setting of treatment \\
\hline TreatLoc & Correctional setting of treatment \\
\hline CompLoc & Correctional setting of comparison group \\
\hline StaffCred & Type of treatment staffing \\
\hline TreatLength & Length of primary treatment in weeks \\
\hline TreatAfter & Does treatment contain an aftercare component \\
\hline TreatN & Treatment group sample size \\
\hline CompN & Comparison group sample size \\
\hline TreatR & Treatment group recidivists \\
\hline CompR & Comparison group recidivists \\
\hline Male & Whether the sample was all male or mixed genders. \\
\hline AUTHOR & Authors names were recorded \\
\hline
\end{tabular}

After each study was examined a coding form was completed and filed for the study.

Later the forms were referred to for data entry and logged into SPSS. 


\section{DATA COLLECTION}

\section{The Effect Size Statistic}

The odds-ratio will be our effect size statistic of concern in this meta-analysis. The odds-ratio compares two groups in relation to their relative odds of a status or event, such as a group of inmates who receive drug treatment compared to a group of inmates who do not receive drug treatment in relation to the odds they recidivate. To explain the odds-ratio, we must first explain odds, where $p=$ probability of the event. Odds are defined as:

$$
\text { Odds of an event }=\frac{p}{1-p}
$$

Lipsey and Wilson (2001:52) give an excellent description and interpretation of the oddsratio in relevant terms to this study:

For example, if the probability of a successful outcome of treatment is .25 , then the odds of that outcome are .33, that is, .25/(1-.25). Thus, the odds of a successful outcome, given treatment, are 1 to 3 (one success to three failures), whereas the probability of a successful outcome is 1 in 4 (one success in four cases). Suppose that, for the control group, the probability of a successful outcome is .20. The odds of a successful outcome, given no treatment are then .25 , that is $.20 /(1-.20)$. From the odds of success for the treatment and control groups, we can calculate the odds-ratio, which is the ratio of those two odds, that is, $.33 / .25$ or 1.33 . For this fictitious data, the odds of a successful outcome are 1.33 times greater for the treatment group than the control group.

Since this study examines dichotomous variables, the odds-ratio is the most relevant effect size calculation. However, the inconvenient form of odds-ratios being centered around 1 rather than 0 can be confusing. An odds-ratio of 1 indicates no 
relationship, values between 0 and 1 indicate a negative relationship and values greater than 1 provide a positive relationship. This makes interpretation difficult, meaning that an odds-ratio of .5 and an odds-ratio of 2 have the same relationship but in the opposite direction. To better understand this complicated relationship, let us examine the interpretation of group A with a .5 odds-ratio compared to group B with the odds-ratio of 2 relative to a control/treatment group scenario. The odds for a successful outcome for group B are 2 times greater for the treatment group than the control group. Since the relationship is the same, simply in opposite directions, for group A the odds of a successful outcome are 2 times greater for the control group than the treatment group. In order to compensate for this, and follow the meta-analysis guidelines set forth in the literature, our analysis will be performed on the natural log of the odds ratio.

The distributional form of the logged odds-ratio is approximately normal with a mean of 0 and a standard deviation of 1.83. Thus, a negative value reflects a negative relationship and a positive value reflects a positive relationship. An additional advantage of using the logged odds for calculation purposes is that the standard error becomes easy to calculate (Lipsey and Wilson 2001:53).

By transforming our effect size variable (ES) to the natural log of the odds-ratio, it will exhibit a negative relationship if less than zero, no relationship if equal to zero, and a positive relationship if greater than zero. To transform our Odds-Ratio we take the natural log:

$$
\mathrm{ES}_{\mathrm{LOR}}=\ln [\mathrm{OR}]
$$

Logged Odds can always be converted back to the Odds-Ratio by using the inverse natural log function:

$$
\mathrm{OR}=\mathrm{e}^{\mathrm{ESLOR}}
$$


Each study has an Odds-Ratio calculated for it, then each Odds-Ratio is transformed on the natural log. This serves as the effect size variable for our studies; each study has one ES. However, since studies usually vary in population size, we want to weight our ES. The studies contained in a meta-analysis are composed of different sized populations, and since a study that has a population of 1000 is believed to be a more accurate representation of the general population than a study of 10 , we want the larger study to carry more weight or have a larger effect on our findings than the smaller study. It is simple to just weight each ES by its sample size; however, it is more accurate to weight it by the inverse variance.

In order to calculate our inverse variance weight, we first have to figure the standard error (se) of our ES. The standard error is a measure of accuracy for our ES. The smaller the se, the more accurate the ES statistic. For Logged Odds-Ratio's se is calculated as:

$$
s e=\sqrt{(1 / a)+(1 / b)+(1 / c)+(1 / d)}
$$

*where $a, b, c$, and $d$ are the cell frequencies of a 2 by 2 contingency table*

The inverse variance weight $(w)$ is then calculated from the standard error $(s e)$ :

$$
w=1 /\left(s e^{2}\right)
$$

The results of each studies $\mathrm{ES}_{\mathrm{LOR}}, w$, and se are recorded in Table 1 with reference to the studies ID number. A forest plot of the logged odds-ratios was composed (Figure 2) to illustrate the distribution of their ES. 


\section{Analyzing and Describing the Distributions of Effect Sizes}

Now that each study has an ES calculated along with its $w$ and $s e$, the calculation

of the Weighted Mean Effect Size ( $\overline{\mathrm{ES}}$ ) can now be carried out, providing the outcome variable of concern for this meta-analysis. From Table 1 and Figure 2, the Weighted Mean Effect Size ( $\overline{\mathrm{ES}}$ ) and its standard error $\left(s e_{E S}\right)$ were calculated by the following method:

$$
\overline{E S}=\frac{\sum(w \times E S)}{\sum w} \quad s e \overline{E S}=\sqrt{\left(1 / \sum w\right)}
$$

The $\overline{E S}$ is -0.5623 and the $s \overline{E S}$ is 0.0636 .

Next a Z-test and 95\% Confidence Interval were obtained as follows:

$$
\begin{gathered}
\mathrm{z}=\frac{\overline{E S}}{s e \overline{E S}} \\
95 \% \text { Confidence Interval } \\
\text { Lower }=\overline{E S}-1.96(s e \overline{E S}) \\
\text { Upper }=\overline{E S}+1.96(s e \overline{E S})
\end{gathered}
$$

The Z-Test for the $\overline{E S}$ is -8.8412 . The $95 \%$ Confidence Interval has a lower value of -0.6870 and an upper value of -0.4376 .

A Homogeneity test must be run to determine whether the assumption that all of the effect sizes are estimating the same population mean is reasonable. Homogeneity is determined through the Q Statistic. If homogeneity is rejected then the distribution of effect sizes is heterogeneous. $Q$ is calculated as follows: 


$$
Q=\sum\left(w \times \overline{\mathrm{ES}}^{2}\right)-\left\{\left[\sum(w \times \overline{\mathrm{ES}}]^{2} / \sum w\right\}\right.
$$

We also have to calculate the degrees of freedom (df) which is the number of ES's - 1. So my Degrees of freedom are 11 . The critical value for Chi-Square with $\mathrm{df}=11$ and $\mathrm{p}=.05$ is 19.68 . Since my calculated Q [ 170.7655$]$ is much greater than 19.68 , we can reject the null hypothesis of homogeneity. Thus the variability across effect sizes DOES exceed what would be expected based on sampling error. My distribution of effect sizes is assumed to be heterogeneous.

\section{Analyzing Relationships with Moderator Variables}

Heterogeneity maybe caused by a single mean ES, which is not a good descriptor of the distribution or that there are real between study differences; that is, studies estimate different population mean effect sizes. So next, the analog to the one way ANOVA was computed to examine excess between study effect size variability.

According to the methods presented by Lipsey and Wilson (2001), the variables of the treatment setting and whether or not the program contains an aftercare component, explain our heterogeneity. The setting in which treatment was received can explain the between group differences, as illustrated by Table 3 in the results section.

The rehabilitative model containing an aftercare component, defined as any type of post release counseling or therapy, can also explain our heterogeneity as illustrated by Table 4 in the results section.

The possibility of selection and publication bias was also examined by constructing a funnel plot (See Figure 3) of the effect sizes against the inverse variance weights, and used methods outlined by Egger (Egger and Davey-Smith 1998). $\mathrm{I}^{2}$ 
calculations were also computed to identify the magnitude of between study differences (Huedo-Medina, Sanchez-Meca, and Marin-Martinez 2006). 


\section{RESULTS}

Each study had an effect size (ES) calculated as well as its inverse variance weights $(w)$, and its standard error (se). Those values were recorded in Table 1 below and referenced to each study. It is important to note that the results in Table 1 are logged-odds ratios, meaning that the negative numbers show a reduction in recidivism and the positive numbers show an increase in recidivism over the control groups.

Table 1.

\begin{tabular}{|c|c|c|c|}
\hline Study & ES & $\boldsymbol{w}$ LoR & se \\
\hline Prendergast et al. 2004 & -0.4804 & 21.4283 & 0.2160 \\
\hline Staton-Tindal et al. 2009 & -3.0017 & 16.7504 & 0.2443 \\
\hline Zanis et al. 2003 & -0.5915 & 13.8556 & 0.2687 \\
\hline Inciardi et al. 1997 & -0.5045 & 26.6726 & 0.1936 \\
\hline Prendergast et al. 2003 & -0.3105 & 33.9388 & 0.1717 \\
\hline Belenko et al. 2005 & -0.8238 & 14.5546 & 0.2621 \\
\hline Messina et al. 2006 & 0.4357 & 16.5622 & 0.2457 \\
\hline Pelissier et al. 2001 & -1.8317 & 14.3675 & 0.2638 \\
\hline Dynia, P \& Sung, H. 2000 & -1.0536 & 11.4567 & 0.2954 \\
\hline Hiller et al. 1999 & -0.4410 & 18.0985 & 0.2351 \\
\hline Zhang et al. 2011 & 0.1134 & 49.6141 & 0.142 \\
\hline Miller, J. \& Miller, H. 2011 & -0.0735 & 9.9033 & 0.3178 \\
\hline
\end{tabular}

To better visually represent this data, a forest plot (Figure 2) was constructed to display the distribution of the data from the individual studies contained in the analysis. Once again these figures are expressed as the logged-odds ratios, meaning that those falling below the " 0 " line indicate a reduction in recidivism and those above the " 0 " line display an increase of recidivism over the control group. Included in the forest plot is the $s e$, this is to give the best visual representation of exactly where the ES may fall on the 
plot given the statistics accuracy.

Figure 2. Forest plot of the 12 Odds-Ratios (logged) included in analysis

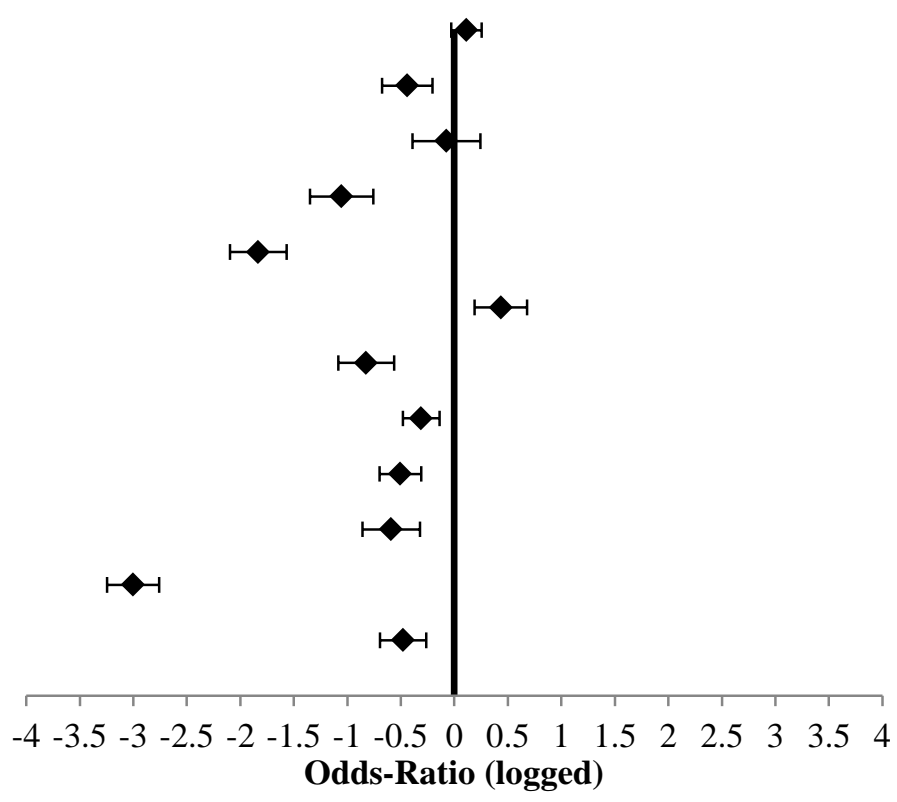

Zhang et al. 2011

Hiller et al. 1999

Miller J. and Miller H. 2011

Dynia and Sung 2000

Pelissier et al. 2001

Messina et al. 2006

Belenko et al. 2005

Prendergast et al. 2003

Inciardi et al. 1997

Zanis et al. 2003

Staton-Tindal et al. 2009

Prendergast et al. 2004

It is important to reiterate that the findings of meta-analytic methods are an analysis of the literature rather than subjects. That being said, the trends in the literature following the era of indeterminate sentencing are showing that incarceration-based rehabilitation does significantly reduce recidivism rates (Table 2). On average those who receive incarceration-based rehabilitation are $43 \%$ less likely to recidivate than those inmates who did not receive incarceration-based rehabilitation, maintaining a high level of significance $\left(\mathrm{p}<0.0001, \mathrm{I}^{2}=93.56\right)$. My hypothesis that incarceration-based rehabilitation during the era of determinate sentencing will reduce recidivism is substantiated. The results presented are from a fixed effects meta-analysis as these results show the most conservative percentage reduction in the odds of recidivism. However, due to heterogeneity in the data, the null hypothesis that a fixed effects model is more appropriate than a random effects model is rejected (via a test for whether the random 
effects variance component equals zero; $\mathrm{p}=.0387$ ). The random effects model indicates a $51.75 \%$ reduction in the odds of recidivism $($ Mean $\mathrm{ES}=0.4925 ; 95 \% \mathrm{CI}=0.2986$, $0.8121 ; \mathrm{p}=.0055)$.

Table 2

Meta-Analysis of the Effectiveness of Incarceration-Based Rehabilitation Mean Effect Sizes

\begin{tabular}{|c|c|c|c|c|c|}
\hline Variables & Mean ES & $95 \%$ C.I. & Value for Q-test & $\mathrm{I}^{2}$ & $\mathrm{~K}$ \\
\hline $\begin{array}{l}\text { Incarceration-based } \\
\text { Rehabilitation }\end{array}$ & $0.5699 * * *$ & $0.5031,0.6455$ & 0 & 93.56 & 12 \\
\hline $\begin{array}{l}\text { Incarceration-based } \\
\text { Rehabilitation } \\
\text { Without Aftercare } \\
\text { Component }\end{array}$ & $0.1937 * * *$ & $0.0867,0.4328$ & 0.0565 & 65.2 & 3 \\
\hline $\begin{array}{l}\text { Incarceration-based } \\
\text { Rehabilitation } \\
\text { With Aftercare } \\
\text { Component }\end{array}$ & 0.6678 & $0.04233,1.0536$ & 0.6026 & 0 & 9 \\
\hline $\begin{array}{l}\text { Incarceration-based } \\
\text { Rehabilitation } \\
\text { Conducted in } \\
\text { Group Setting }\end{array}$ & $0.4268 * *$ & $0.2357,0.7730$ & 0.1647 & 32.99 & 8 \\
\hline $\begin{array}{l}\text { Incarceration-based } \\
\text { Rehabilitation } \\
\text { Conducted in Mixed } \\
\text { Settings }\end{array}$ & 0.6594 & $0.2828,1.5376$ & 0.6694 & 0 & 4 \\
\hline
\end{tabular}

Abbreviations: ES=Effect size, C.I.= Confidence Interval, $\mathrm{K}=$ Number of Studies

$\star \mathrm{P}<.05, \quad * * \mathrm{P}<.01, \quad * \star * \mathrm{P}<.001$

*Mean ES and 95\% CI are the exponent of the computed values (OddsRatios).

The large Q statistic identified heterogeneity within the meta-analysis data, indicating that variability across the effect sizes is more than what would be expected based on sampling error alone. The studies within the meta-analysis were actually 
estimating different population mean effect sizes, providing real between study

differences. Upon closer examination, two subgroups were isolated as the sources of heterogeneity: the setting in which the rehabilitation took place and whether or not the rehabilitative model contained an aftercare component.

Those who participated in rehabilitation that took place in a group setting were $57 \%$ less likely to recidivate than those who were in the control groups $(\mathrm{p}<0.01$, $\mathrm{I}^{2}=32.99$ ). While those who participated in a rehabilitative model that consisted of mixed settings (individual, group, family, etc.) illustrate no difference from the control, thus revealing a source of heterogeneity (Table 2). The $\mathrm{I}^{2}$ statistic for this group is 0 .

When it came to the aftercare component, we had similar findings and identified another source of heterogeneity (Table 2). Those inmates whose rehabilitative models did not consist of an aftercare component were $81 \%$ less likely to recidivate than the control groups ( $\mathrm{p}<0.001, \mathrm{I}^{2}=65.2$ ). Those inmates whose rehabilitative model did consist of an aftercare component displayed no significant difference than the control groups ( $p>0.05$, $\left.\mathrm{I}^{2}=0\right)$.

Other subgroups such as treatment staff credentials, treatment locations, and whether the sample was all male were examined. These subgroup analyses were dismissed. Since the meta-analysis began with a small sample size of 12 , when subgroups were broken down, many of the subgroups were left with a $\mathrm{K}$ of 1 . This caused the subgroup analysis to be voided, making them insignificant.

I composed a funnel plot of the studies effect sizes against their inverse variance weights (Figure 3) to utilize an Egger's Test in order to see if publication or selection bias was present. 


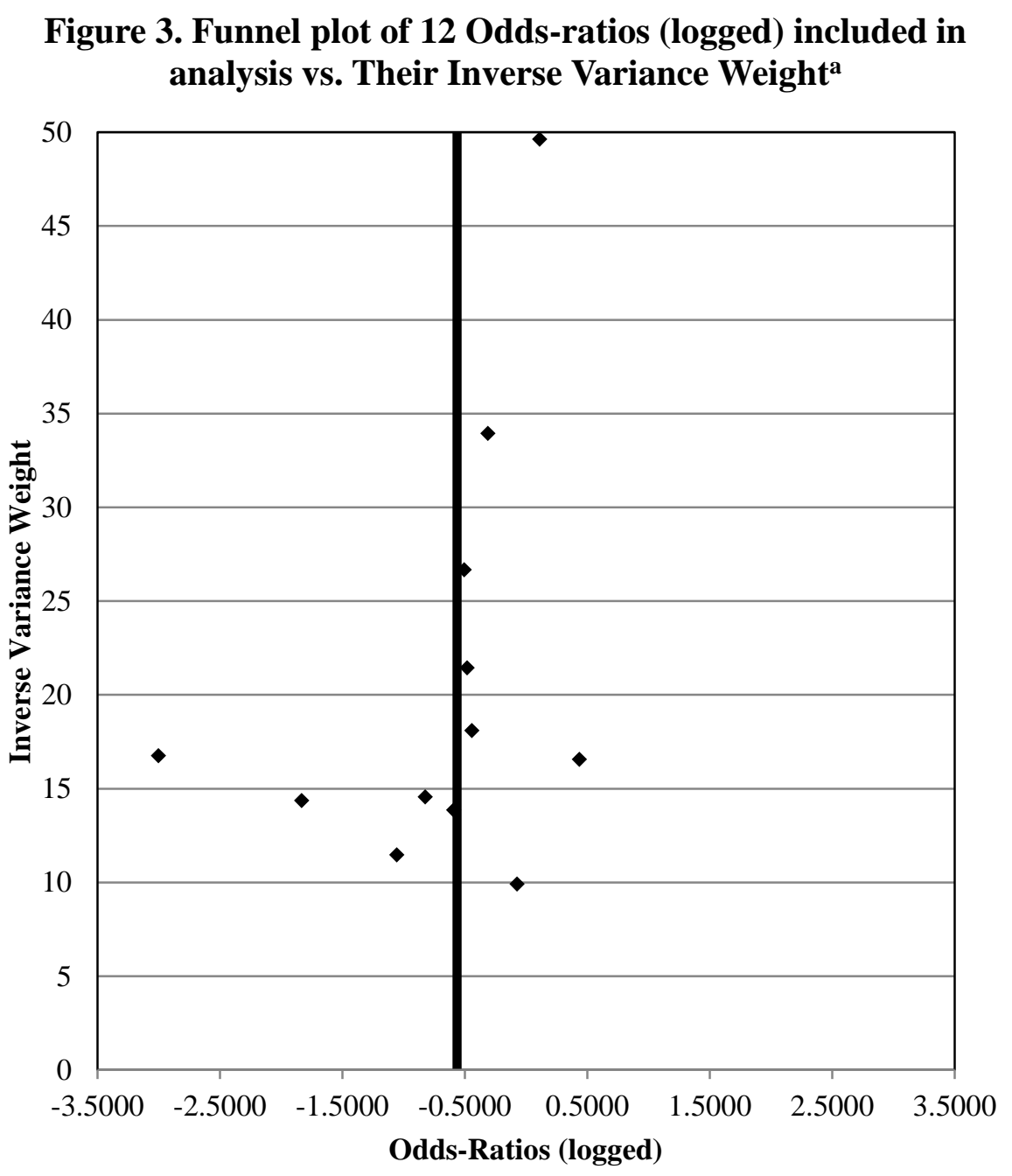

a Vertical line denotes the mean log odds-ratio of -0.5623 .

Egger's test detects publication bias by regressing the standard normal deviate against the estimate's precision. The standard normal deviate is defined as the odds ratio divided by its standard error, while the precision is the inverse of the standard error. This gives us the regression equation of $\mathrm{SND}=\mathrm{a}+\mathrm{b}$ (precision) (Egger and Davey-Smith 1998). 
According to the visible asymmetry across the smaller studies (Figure 3), it appears that there was a slight publication bias in the direction of those studies predicting rehabilitation reduced recidivism. When the formal Egger's test was calculated, it produced a p-value of .054, indicating a non-significant constant allowing for the formal claim of funnel plot symmetry. The p-value from the Eggers test is marginal however, indicating the possibility of some publication bias. An examination of the funnel plot shows that if any studies are missing from the analysis they are likely those with small sample sizes that found an increase in recidivism following rehabilitation. 


\section{DISCUSSION}

\section{The Story Told by the Data}

As hypothesized, incarceration-based drug rehabilitation does have a significant effect on reducing recidivism. The components of rehabilitation vary from program to program and facility to facility, but the overall trend demonstrates that rehabilitation does show a reduction in recidivism. Surprisingly, I did not expect to find that a group setting rehabilitation provides stronger evidence for recidivism reduction than a mixed setting style of rehabilitation. A rehabilitation model that does not consist of an aftercare component was not expected to have a stronger effect on recidivism reduction than one that does have an aftercare component.

The disparity between other current literature and my findings on the aftercare component raised some concern. A closer look was taken at the three studies whose programs did not contain an aftercare component to find out if they had similar populations that differed from the studies whose programs did contain an aftercare component. The three studies in question were found to have some interesting content that should be pointed out concerning the meta-analysis' findings on the aftercare component. The first study consisted of a prison-based evaluation of a therapeutic community in Kentucky. It did report on its follow-up findings; while the program did not require offenders to participate in an aftercare program, it was highly encouraged. Forty-four percent of participants did take the programs advice and enrolled in some form 
of post-release aftercare on their own accord. It is important to note that while the study was coded as not requiring the participants to utilize aftercare, many participants reported that they had sought out post-release aftercare on their own. The other two studies were found to examine the same Residential Substance abuse program in Kings County, New York. The program is a Treatment Alternative-to-Prison (TAP) program, in which the offender agrees to participate in a residential substance abuse treatment program (which still takes place in a lock down facility, 24/7 supervision). In return for the participant's successful completion of the program lasting 15-24 months, the prosecutor's office drops all official charges. However, those who do not complete the program or violate protocol are immediately transferred to prison and all original criminal charges are applied to their sentence. The TAP program these two studies investigate varies from traditional RSAT programs. First, TAP programs last longer than traditional RSAT programs, extending up to two years. Next, they use a very selective screening process; the legal case itself is screened by the prosecutor (weak legal cases, major drug dealers, drugs sales near schools, offenders with a violent history, and those with severe psychological disorders are all dismissed from further contemplation), and the probation/parole office, the judge, and a treatment professional all participate in the screening process. The treatment itself (intensive individual and group counseling) is performed by private, not-for-profit treatment agencies, not correctional staff. However, the TAP program does not require participants to use an aftercare component, but like the Kentucky program, they do encourage it. Unlike the study on Kentucky's program, the two examining the TAP program do not have follow-up data reporting whether or not participants sought aftercare 
on their own accord or not, so we really have no way of knowing beyond a doubt that these participants did not have any aftercare.

While the meta-analysis on the surface provides an interesting finding on the aftercare component, upon closer examination of the three studies composing this finding, it should be taken cautiously. Just because the programs themselves did not require the participants to enroll in after programs or self-help groups, participants may have done so on their own.

\section{Theoretical Insights}

According to the labeling theory, the relabeling of "Prisons" as punishment oriented housing for societies' evil, to the "Correctional Facilities" that rehabilitate the criminally defective, has shown a little success. Rather than just storing the inmates, this study shows that when given the opportunity to try to rehabilitate themselves (not based on time reductions, but just for self-betterment), there is a significant chance for the inmates to reduce their odds of being re-incarcerated. In order for this to occur, the justice system has to recognize that the problem with the penal system is rooted in the deterrence theory and move toward one which is theoretically rooted in treatment. Since a correctional facility controls the opportunities placed before the inmates, it is important for the facility to adopt the treatment philosophy and allow opportunities for rehabilitation to occur within its walls.

Once released, if the inmate can effectively renegotiate their label and accept the new role of a rehabilitated person, while supporting the concepts instilled in them through the incarceration-based rehabilitation, then the possibility for them to migrate away from crime exists, as supported by this study. While it is still possible for society to deny their 
new label, it is a stepping stone in the right direction for the inmate. Policies such as those that deny financial aid or employment opportunities for felons can serve as examples of how society can still deny the inmate's new label and force them back into a Self-Fulfilling Prophecy of crime.

\section{Policy Implications}

The justice system is reluctant and slow to implement change; this is partially due to cautionary reasons as well as budgetary restraints. The rehabilitative model is often resisted because of its large upfront cost to the justice system. However, the long-term savings of rehabilitation is undeniably beneficial to the system. By reducing recidivism, the rehabilitative model ultimately saves the justice system from having to house and reprocesses the same offenders again and again. We have already seen a shift toward the rehabilitative model in the justice system, but there are still those who do not believe it is cost effective and that government money could be more effectively used other places. Based on the results of this study, I estimate that the justice system could reduce the number of re-offenders by $43 \%$. This estimate is justified by the mean effect size statistic that was produced by synthesizing the data across 12 studies of U.S. facilities, during the determinate sentencing era, implementing rehabilitation programs on adult populations in comparison to a control group who did not receive the treatment. Just imagine how much savings that would provide the justice system. By reducing the number of re-offenders, the system would not only benefit monetarily, but also would not need the extra time and staffing to process offenders. This would translate into huge savings and a more efficient system. 
While rehabilitation is not going to be the "end all" to crime, it is definitely a more effective philosophy than "treatment as usual" as supported by this study. With the implementation of innovative programs such as drug courts, and legalization or decriminalization of victimless crimes, we as a country are well on our way to reducing the monetary cost of the justice system, and creating a more effective system designed to cope with crime.

\section{Limitations of This Study, Call For Further Research}

As with any meta-analysis, there are certainly a fair number of limitations, more so than with a traditional study that generates a primary source of data. The key to remember when using meta-analytic methods is that the researcher cannot introduce research questions or examine variables that are not already there. As is the case with this study, my dependent and independent variables computed nicely, but when it comes to calculating subgroups, calculations become difficult quickly. I was unable to examine many subgroups that I would have liked to examine, because they were not present within the primary research.

One of my largest limitations in this study was my strict criteria of inclusion. I had hoped to make a strong stance on comparing 'apples to apples' by excluding many studies that did not compare like groups with like groups. I made restrictions on inclusion based on geographic location, age, date, publication type, and study design in an effort to make a more robust and valid representation of the data. However, I limited myself to 12 studies that met my criteria of inclusion. For future research, a more lenient criteria of inclusion maybe desirable, at least until more research on the topic is available. 
Further research that could build on this meta-analysis would be a meta-analytic look at the effectiveness of incarceration-based rehabilitation during the indeterminate sentencing era. Using the same stringent criteria of inclusion on an earlier era would give a good comparative idea of the inmate's motivation for participating in rehabilitation during the indeterminate sentencing era. It would also allow us to see the effectiveness of rehabilitation relative to date, and clarify whether or not the philosophies of our justice system are moving in the right direction. 


\section{REFERENCES}

Adams, Mike S., Craig T. Robertson, Phyllis Gray-Ray, and Melvin C. Ray. 2003. "Labeling and Delinquency." Adolescence 38:171-186.

Alcoholics Anonymous. 2001. Alcoholics Anonymous (Fourth Edition). New York, NY: A. A. World Services.

Andrews, D.A., Zinger, Ivan, Hoge, Robert D., Bonta, James, Gendreau, Paul, Cullen, Francis T. 1990. "Does Correctional Treatment work? A Clinically Revelant and Psychologically Informed Meta-Analysis," Criminology 28, 3: 369-404.

Austin, James and Irwin, John. 2001. Its About Time America's Imprisonment Binge (Third Edition). Belmont, CA: Wadsworth.

Banks, Duren and Gottfredson, Denise C. 2003. "The Effects of Drug Treatment and Supervision on Time to Rearrest Among Drug Treatment Court Participants." Journal of Drug Issues 22:385-412.

Becker, Howard. 1963. Outsiders: Studies in the Sociology of Deviance. New York: Free Press.

Belenko, Steven., Foltz, Carol., Lang, Michelle A., and Sung, Hung-En. 2005. "Recidivism Among High-Risk Drug Felons." Journal of Offender Rehabilitation 40.1-2: 105-132.

Bernburg, Jon G., Marvin D. Krohn, and Craig J. Rivera. 2006. "Official labeling, criminal embeddedness, and subsequent delinquency: A longitudinal test of Labeling Theory."Journal of Research in Crime and Delinquency 43:67-88.

Best, Joel. 2004. Deviance; career of a concept. California: Wadsworth.

Brownmiller, Susan. 1975. Against Our Will: Men, Women, and Rape. New York: Simon and Schuster. 
Bureau of Justice Assistance. 2005. Residential Substance Abuse Treatment for State Prisoners (RSAT) Program. Washington D.C.: United States Department of Justice

Carson, E. Ann, and Sabol, William J. 2012. "Prisoners in 2011." Washington, DC: U.S. Department of Justice: Bureau of Justice Statistics. Retrieved March 1, 2013 (http://bjs.ojp.usdoj.gov/content/pub/pdf/p11.pdf).

Caulkins, Jonathan P. 1997. Mandatory Minumum Drug Sentences: Throwing Away the Key or the Taxpayers' Money? Santa Monica, CA: RAND Corporation. xvii-xviii.

Clear, Todd R. and Gallagher, Kenneth W. 1985. "Probation and Parole Supervision: A Review of Current Classification Practices." Crime and Delinquency 31:423-443.

Cooley, Charles H. 1902. Human Nature and the Social Order. New York: Scribners and Sons.

Cousineau, F.D. and Plecas, D.B. 1982. "Justifying Criminal Justice Policy with Methodologically Inadequate Research." Canadian Journal of Criminology 24.3:307-321.

Durkhiem, Emile. 1951 (1897). Suicide. Glencoe, IL: Free Press.

Dyer, Joel. 2000. The Pertpetual Prisoner Machine: How America Profits from Crime. Boulder, CO: Westview Press.

Dynia, Paul and Sung, Hung-En. 2000. "The Safety and Effectiveness of Diverting Felony Drug Offendersto Residential Treatment as Measured by Recidivism." Criminal Justice Policy Review 2000 11:299-311.

Egger, Matthias, and George Davey-Smith. 1998. "Meta-analysis: Bias in Location and Selection of Studies." British Medical Journal 316(7124):61-66.

Fiske, S. and Sundeen, R.A. 1982. "Local Resistance to Community-based care facilities."Journal of Offender Counseling, Services, and Rehabilitation 6.4:2942.

Garland, David. 1990. Punishment and Modern Society: A Study in Social Theory. Chicago, IL: University of Chicago Press.

Gendereau, Paul and Ross, Robert R. 1987. "Revivification of Rehabilitation: Evidence From the 1980s." Justice Quarterly 4.3: 349-407.

Glass, Gene V., McGaw, Barry, and Smith, Mary L. 1981. Meta-Analysis in Social Research. Beverly Hills, CA: Sage. 
Goffman, Erving. 1963. Stigma: Notes on the management of spoiled identity. Englewood Cliffs, NJ: Prentice-Hall.

Gonzales, Alberto R., Henke, Tracy A., and Herraiz, Domingo S. 2005. "Residential Substance Abuse Treatment for State Prisoners (RSAT) Program." Washington DC: U.S. Department of Justice: Office of Justice Programs. Retrieved March 1, 2013 https://www.ncjrs.gov/pdffiles1/bja/206269.pdf

Goode, Erich. 1991. "Positive Deviance.” Deviant Behavior 12: 289-309.

Gordon, Marshall 1998. "self-fulfilling prophecy." Encyclopedia.com. Retrieved March 20, 2009 from: http://www.encyclopedia.com/doc/ 1088selffulfillingprophecy.html

Gouldner, Alvin W. 1968. "The sociologist as a Partisan: Sociology and the welfare state.” American Sociologist 3:103-116.

Hanser, Robert D. 2010. Community Corrections. Thousand Oaks, CA: SAGE Publications.

Hiller, Matthew L., Knight, Kevin., and Simpson, Dwayne D. 1999. "Prison-Based Substance Abuse Treatment, Residential Aftercare and Recidivism." Addiction 94.6: 833-842.

Huedo-Medina, T. B., Sanchez-Meca, J., and Marin-Martinez, F. 2006. "Assessing heterogeneity in meta-analysis: Q statistic or I2 index?" Psychological Methods, 11.2: 193-206.

Humphreys, Laud. 1972. Out of the Closets: The Sociology of Homosexal Liberation. Englewood Cliffs, NJ: Prentice Hall.

Inciardi, James A., Martin, Steven S., Butzin, Clifford A., Hooper, Robert M., and Harrison, Lana D. 1997. "An Effective Model of Prison-Based Treatment for Drug-Involved Offenders.” Journal of Drug Issues 27.2: 261-278.

Lemert, Edwin M. 1967. Human Deviance, Social Problems, and Social Control. Englewood Cliffs, NJ: Prentice Hall.

Liazos, Alexander. 1972. "The poverty of the sociology of Deviance: Nuts, Sluts, and Perverts." Social Problems 20:103-120.

Linden, Rick and Perry, Linda. 1982. "The Effectiveness of Prison Education Programs." Journal of Counseling, Services, and Rehabilitation 6.4: 43-57.

Lindesmith, Alfred R. 1947. Opiate Addiction. Bloomington, IN: Principia. 
Lipsey, Mark W. 1985. "The paradox of effect Size: Too Small to Detect, Too Big to Neglect." Paper presented at the Canadian Evaluation Society, Evaluation Network and the Evaluation Research Society, Toronto.

Lipsey, Mark W. 1986. "Research Plan: Meta-Analysis of Juvenile Delinquency Treatment Research."Unpublished Manuscript. Cleremont Graduate School.

Lipsey, Mark W. and Wilson, David B. 2001. Practical Meta-analysis. Thousand Oaks, CA: Sage.

Lipton, Douglas S. 1998. "Therapeutic communities: history, effectiveness, and prospects." Corrections Today 60.6: 106-113.

Logan, Charles H. and Gaes, Gerald G. 1993. "Meta-Analysis and the Rehabilitation of Punishment" Justice Quarterly 10.2: 245-263.

Martinson, Robert. 1974. "What Works?- Questions and Answers about Prison Reform." The Public Interest 35: 22-54.

Martinson, Robert. 1979. "New findings, new views: A note of caution regarding prison reform." Hofstra Law Review 7:243-258.

Maruschak, Laura M. and Parks, Erika. 2012. "Probation and Parole in the United States, 2011." Washington DC: U.S. Department of Justice: Bureau of Justice Statistics. Retrieved March 1, 2013 (http://bjs.ojp.usdoj.gov/content/pub/pdf/ppus11.pdf).

Mauer, Marc. 2006. Race To Incarcerate The Sentencing Project. New York, NY: The New Press.

McAuliffe, William E. and Robert A. Gordon. 1974. "A test of Lindesmith's theory of addiction.” American Journal of Sociology 79: 795-840.

McCaffrey, Barry. 1998. Drug Treatment in the Criminal Justice System. Washington DC: Office of National Drug Control Policy.

Mead, George H. 1964. Mind, Self, and Society. Chicago: University of Chicago Press.

Meade, Anthony C. 1974. "The Labeling approach to delinquency: State of the theory as a function of method." Social Forces 53:83-91.

Melossi, Dario. 1985. "Overcoming the crisis in critical criminology: Toward a grounded labeling theory." Criminology 23:193-207.

Merton, Robert K Social Theory and Social Structure. 2nd Revised Edition. New York: Free Press, 1968 
Messina, Nena, Burdon, William, and Prendergast, Micheal. 2006. "Prison-Based Treatment for Drug-Dependent Women Offenders: Treatment Versus No Treatment." Journal of Psychoactive Drugs Nov supplement 3: 333-343.

Miller, Mitchell J., Miller, Holly V. 2011. "Considering the Effectiveness of Treatment Behind Bars: Findings From the South Carolina RSAT Evaluation.” Justice Quarterly 28.1: 70-86.

Mitchell, Ojmarrh, Wilson, David B., and MacKenzie, Doris L. 2007. "Does incarceration-based drug treatment reduce recidivism? A meta-analytic synthesis of the research." Journal of Exp Criminology 3:353-375.

Nixon, Gary and Solowoniuk, Jason. 2008. "Moving beyond the 12-steps to a second stage recovery: A phenomenological inquiry." Journal of Groups in Addiction \& Recovery, 3(1-2), 23-46.

Orsagh, Thomas and Marsden, Mary Ellen. 1985. "What Works When: Rational- Choice Theory and Offender Rehabilitation." Journal of Criminal Justice 13.3: 269-277.

Palmer, Ted. 1984. "The Effectiveness Issue Today: An Overview." Federal Probation 46: 3-10.

Pearson, Frank S. and Lipton, Douglas S. 1999. "A Meta-Analytic Review of the Effectiveness of Corrections-Based Treatments for Drug Abuse." The Prison Journal 79:384-410.

Pelissier, Bernadette., Wallace, Susan., and Ann, Joyce. 2001.'Federal Prison Residential Drug Treatment Reduces Substance Use and Arrest After Release." American Journal of Drug \& Alcohol Abuse 27.2: 315-337.

Prendergast, Michael L., Hall, Elizabeth A., Wexler, Harry K. 2003. "Multiple Measures of Outcome in Assessing a prison-Based Drug Treatment Program." Journal of Offender Rehabilitation 37.3-4: 65-94.

Prendergast, Michael L., Hall, Elizabeth A., Wexler, Harry K., Melnick, Gerald., and Cao, Yan. 2004. "Amity Prison-Based Therapeutic Community: 5-Year Outcomes." The Prison Journal 84: 36-60.

Reiman, Jeffery, \& Leighton, Paul. 2010. The rich get richer and the poor get prison; Ideology, class, and criminal justice (ninth edit.). Boston, Ma: Allyn \& Bacon.

Richards, Stephen C. and Jeffrey I Ross. 2002. Behind Bars; Surviving Prison. Indianapolis, IN. Alpha Books. 
Richards, Stephen C. and Jeffrey I. Ross. 2003. Convict Criminology. Belmont, CA: Thomson Wadsworth.

Rotman, Edgardo. 1986. "Do Criminal Offenders Have a Constitutional Right to Rehabilitation?" Journal of Criminal Law and Criminology 77: 1023-1068.

Sabol, William J., Heather C. West, and Matthew Cooper. 2009. Prisoners in 2008. Washington, DC: Bureau of Justice Statistics. Retrieved on February 18, 2010 from: http://bjs.ojp.usdoj.gov/content/pub/pdf/p08.pdf.

Schervish, Paul G. 1973. "The labeling Perspective: Its bias and potential in the study of political deviance." American Sociologist 8:47-57.

Sechrest, Lee, White, Susan O., and Brown, Elizabeth D. 1979. The Rehabilitation of Criminal Offenders:Problem and Prospects. Washington D.C.: National Academy Press.

Snyder, Howard N. 2011. "Recidivism rates of prisoners with selected characteristics released in 1994 from prisons in 15 States." Washington, DC: Bureau of Justice Statistics. Retrieved March 1, 2013 (http://bjs.ojp.usdoj.gov/index.cfm? ty=datool\&surl=/recidivism/index.cfm\#).

State of California Department of Alcohol and Drug Programs. 1994. Evaluating Recovery services: The California Drug and Alcohol Treatment Assessment. Sacramento, CA: State of California Department of Alcohol and Drug Programs.

Staton-Tindal, Michele., McNees, Erin., Leukefeld, Carl G., Walker, Robert., Thompson, LaDonna., Pangburn, Kevin., and Oser, Carrie B. 2009. "Systematic Outcomes Research for Corrections-Based Treatment: Implications from the Criminal Justice Kentucky Treatment Outcome Study." Journal of Offender Rehabilitation. 48.8:710-724.

Stohr, Mary K. and Hemmens, Criag K. 2003. The Inmate Experience. Englewood Cliffs, NJ: Prentice Hall.

Tannenbaum, Frank. 1938. Crime and the Community. Boston: Ginn.

Thio, Alex. 1973. "Class bias in the sociology of deviance." American Sociologist 8:1-12.

U.S. Department of Justice, Bureau of Justice Statistics. 1999. Special report on Truth in Sentencing in State Prisons. Washington D.C.: U.S. Government Printing Office.

Van Voorhis, P. 1987. "Correctional Effectiveness: The High Cost of Ignoring Success." Federal Probation 51: 56-62. 
Warr, William. 2011. "The History and Evolution of the Therapeutic Community" Residential Substance Abuse Treatment (RSAT) Training and Technical Assistance (TTA) National Resource Center. Retrieved March 8, 2013 http://www.rsat-tta.com/Files/Trainings/Fulton-County-RSAT-TA-SLIDESFINAL4-7-11-1.

Warren, Carol A.B. 1974. Identity and Community in the Gay World. New York: Wiley.

Whitehead, John T. and Lab, Steven P. 1989. "A Meta-Analysis of Juvenile Correctional Treatment." Journal of Research in Crime and Delinquency 26: 276-295.

Zanis, David A., Mulvaney, Frank., Coviello, Donna., Alterman, Arthur L., Savitz, Barry., and Thompson, William. 2003. "The Effectiveness of Early Parole to Substance Abuse Treatment Facilities on 24-Month Criminal Recidivism." Journal of Drug Issues 223-236.

Zhang, Sheldon X., Roberts, Robert E.L., and McCollister, Kathryn E. 2011. "Therapeutic Community in a California Prison: Treatment Outcomes After 5 Years." Crime and Delinquency 57.1: 82-101. 


\section{CURRICULUM VITAE}

NAME:

ADDRESS:

DOB:

EDUCATION

\& TRAINING:

AWARDS:

\section{PROFESIONAL} SOCIETIES:
Shaun Andrew Dixon

316 Amburgey Dr.

New Albany, IN 47150

Evansville, Indiana - April 11, 1985

B.S., Sociology / Criminal Justice University of Southern Indiana 2003-08

Indiana Academic Honors Diploma 2003

University of Southern Indiana Honors List 2007-08

Biology Club

University of Southern Indiana

2003-04

Sociology Club

University of Southern Indiana

2005-08

Graduate Student Association, Sociology

University of Louisville 2008-11

Alpha Kappa Delta Honor Society, Sociology University of Louisville 2010-13 